May 2016

Word count: $\sim 7000$

\title{
Interface shear box tests for assessing axial pipe-soil resistance
}

\author{
Nathalie Boukpeti $^{1 *}$, David J. White ${ }^{2}$ \\ ${ }^{1}$ Assistant Professor, Centre for Offshore Foundation Systems, The University of Western \\ Australia, Perth \\ ${ }^{2}$ Professor, Centre for Offshore Foundation Systems, The University of Western Australia, \\ Perth \\ ${ }^{*}$ Corresponding Author - address: Centre for Offshore Foundation Systems \\ The University of Western Australia \\ 35 Stirling Highway, Crawley, WA 6009, Australia \\ Email: nathalie.boukpeti@uwa.edu.au \\ Ph. +61 86488 3093, Fax +61 864881044
}

Key words: clays, pipeline, direct shear, interface resistance, consolidation 


\title{
Interface shear box tests for assessing axial pipe-soil resistance
}

\author{
Nathalie Boukpeti, David J. White
}

\begin{abstract}
The clay-interface shear resistance is an important parameter for the design of offshore pipelines, which slide on the seabed as a result of thermally-induced expansion, contraction and lateral buckling. This paper presents a methodology for characterising the clay-interface resistance and quantifying the effect of drainage and consolidation during or in between shearing episodes. Models for describing the clay-interface resistance during planar shearing are presented and compared to test data for a range of drainage conditions from drained to undrained and including the case of episodic consolidation. The test data are from two series of interface shear box (ISB) tests carried out on marine clays. The effects of normal stress level (in the low stress range), over-consolidation and interface roughness are also examined.
\end{abstract}

\section{INTRODUCTION}

Soil-interface resistance is a relevant design parameter for a range of geotechnical structures, e.g., piles, retaining walls, submarine pipelines, skirted foundations, offshore gravity structures and mat foundations. Studies of soil-interface behaviour have been conducted for a variety of soil types (e.g., Potyondy 1961, Yoshimi \& Kishida 1981, Lemos \& Vaughan 2000). These studies are based on experimental investigations using interface shear box (ISB) tests or interface ring shear tests, which have historically been performed as drained tests. Databases of results have been assembled by Ramsey et al. (1998), Jardine \& Chow (2005) and Eid et al. (2014) (with the latter focusing on low stress levels) with the aim of identifying correlations between soil index properties and soil-interface shearing characteristics.

Some studies have considered tests conducted at different rates of shearing, corresponding to various drainage conditions (e.g, Lehane and Jardine 1992, Tika et al. 1996, Ganesan et al. 
2014). In these studies the shear box velocity has generally been varied to achieve either fully undrained or fully drained conditions. However, the drainage process within the shearing soil, and between episodes of shearing, has not been quantified in the interpretation.

The design of offshore structures for deep water developments, such as pipelines and sliding foundations (for example, to support pipeline terminations, Cocjin et al. 2014) requires assessment of the clay-interface shear resistance during sliding events at speeds and over durations that range from drained to undrained conditions. In addition, during the life of the structure, several sliding episodes interspersed with periods of consolidation may take place as the oil or gas production is intermittently started up and shutdown. How to characterise the soil-interface strength for these conditions is the purpose of this paper.

The paper describes a methodology for characterising the clay-interface resistance at low normal stress levels, over a range of drainage conditions from drained to undrained and for the case of episodic consolidation. The influence of normal stress level, interface roughness and over-consolidation is examined.

\section{REVIEW OF PREVIOUS STUDIES}

Studies of the soil-soil or soil-interface shear resistance have been carried out principally using the ring shear test (e.g, Lupini et al., 1981; Lehane \& Jardine, 1992; Lemos \& Vaughan, 2000; Ho et al., 2011) and the direct shear test (e.g., Lehane \& Liu, 2013; Ganesan et al., 2014; Wijewickreme et al., 2014), with fewer studies involving tilt table tests (e.g., Pedersen et al., 2003; Najjar et al., 2007) and cylinder shear tests (Corfdir et al. 2004). Each of these devices has specific advantages and limitations. For example, application of very large shearing displacements can be achieved in a continuous manner with the ring shear apparatus, whereas repeated shearing sequences are necessary with the direct shear box or tilt table apparatus, which may induce some unwanted effects. Another advantage of the ring shear device is that 
it allows for the development of full complementary shear stress. Both the shear box and the ring shear require a strategy to handle the gaps between the two parts of the box and this results in poor stress uniformity. However, the numerical work of Potts et al. (1987) has demonstrated that the stress non-uniformity before failure has little effect on the measured peak shearing resistance.

For the study of interface resistance at very low normal stress, the conventional ring shear device is not well suited due to frictional forces developing between the sides of the sample and the apparatus. To address the issues related to unwanted friction, a number of new or modified direct shear and ring shear devices have been proposed (e.g., White et al. 2012, Ganesan et al., 2014; Wijewickreme et al., 2014; Eid et al., 2014). The simple arrangement of the tilt table means apparatus friction is absent (Najjar et al. 2007).

There are various factors affecting the soil-soil resistance and the interface-soil resistance as reported in the literature: (i) grain size, shape and mineralogy (e.g., Lupini et al., 1981; Stark \& Eid, 1994; Lemos \& Vaughan, 2000; Ho et al., 2011), (ii) normal stress (e.g., Skempton, 1985; Stark \& Eid, 1994; Pedersen et al., 2003; Najjar et al., 2007; White et al., 2012), (iii) interface roughness (e.g., Lemos \& Vaughan, 2000; Ganesan et al., 2014) and hardness (e.g., Dietz, 2000), and (iv) rate of shearing (e.g., Lehane \& Jardine, 1992; Ganesan et al., 2014). This latter factor is partly due to consolidation effects. The influence of shearing rate has also been associated with a change in mode of shearing in soils exhibiting a sliding mode of shear at slow rate, characterised by a brittle response and low residual shear resistance resulting from reorientation of platy particles along the shear surface (Tika et al., 1996; Lemos \& Vaughan, 2000, Fearon et al., 2004). As first recognised by Lupini et al. (1981), soils with more rotund particles exhibit a turbulent mode of shear, characterised by high residual shear resistance and features of classical critical state soil mechanics such as effect of stress history. Due to the relatively small displacements applied during shear box testing (tens of 
millimetres), it is possible that the low residual strengths that can occur in clays that have platy particles may not be exhibited. The work presented in this paper is based on a critical state soil mechanics model of soil behaviour, without the additional aspect of low residual strengths due to the alignment of platy particles during shearing. This approach is adequate to capture the behaviour apparent in a wide range of marine soils from offshore regions throughout the world when tested at low stresses (Najjar et al. 2006, White et al. 2012, Hill et al. 2012).

In this paper, we present a quantitative analysis of the consolidation process taking place during and in between shearing events, which has not been reported before. The analysis is based on the critical state framework and is applied to a series of interface shear box tests data obtained for two marine clays tested at low normal stress. The analysis also incorporates the effects of roughness and normal stress level that are listed above.

\section{FRAMEWORK FOR ASSESSING AXIAL PIPE-SOIL RESISTANCE}

A framework for assessing axial pipe-soil resistance was proposed by White et al. (2012) and Hill et al. (2012) that incorporates the effects of drainage conditions and uses concepts of critical state soil mechanics to describe the changing shear strength of a pipe-soil interface through episodes of shearing and consolidation. Four elements are integrated in the framework (Figure 1): (i) a curved effective stress failure envelope to account for reducing friction angle with increasing stress level, (ii) a drained-undrained transition, associated with pore pressure generation and consolidation, (iii) a transition in interface strength associated with interface roughness, (iv) a wedging effect due to the curved pipe surface. The first three elements of the framework can be quantified for a particular soil through a series of carefully specified interface shear box tests. This will be discussed in detail in Section 5. The models 
used to describe the drained, undrained and partially drained soil-interface resistance are described below.

\subsection{Drained and undrained soil-interface resistance}

\section{Drained resistance}

The drained interface resistance is function of the interface roughness and is described by an effective stress failure criterion in which the friction varies with the effective normal stress, $\sigma^{\prime}$, in the low stress range. A power law relationship may be used to represent the variation of shear strength with $\sigma^{\prime}{ }_{n}$

$\tau_{\mathrm{d}}=\mathrm{a}\left(\sigma_{\mathrm{n}}^{\prime}\right)^{\mathrm{b}} \leq \mu_{\max } \sigma_{\mathrm{n}}^{\prime}$

where $\sigma_{n}^{\prime}$ is the effective normal stress on the shearing interface, expressed in $\mathrm{kPa}$ and $\mathrm{a}, \mathrm{b}$ and $\mu_{\max }$ are constants varying with soil type and interface roughness. During drained shearing, no excess pore pressure is developed so the initial normal stress, $\sigma^{\prime} n$, is also the normal stress at failure. The parameter $\mu_{\max }$ specifies an upper limit on the stress ratio $\tau_{\mathrm{d}} / \sigma^{\prime}$, to avoid unrealistically high friction coefficients as $\sigma_{n}^{\prime}$ approaches zero. The drained stress path during interface shearing is shown schematically in Figure $2 a$ (path $A B$ ). The corresponding path in the semi-logarithmic space of void ratio, e, versus $\ln \sigma_{n}^{\prime}$ terminates on the critical state line (CSL), which has slope $\lambda$ (Figure $2 \mathrm{~b}$ ). Drained shearing up to the critical state induces a change in volume, which can be expressed in terms of the void ratio, $\Delta \mathrm{e}_{\max }$, or the volumetric strain, $\Delta \varepsilon_{\mathrm{v}, \max }$, with $\Delta \mathrm{e}_{\max }=\Delta \varepsilon_{\mathrm{v}, \max }\left(1+\mathrm{e}_{0}\right)$, where $\mathrm{e}_{0}$ is the initial void ratio.

\section{Undrained resistance}

The undrained interface resistance depends on the amount of excess pore pressure, $\Delta u_{\max }$, generated during shearing. This may be expressed as 
$\tau_{\mathrm{u}}=\mathrm{a}\left(\sigma_{\mathrm{n} 0}^{\prime}-\Delta \mathrm{u}_{\max }\right)^{\mathrm{b}}=\tau_{\mathrm{d}}\left(1-\frac{\Delta \mathrm{u}_{\max }}{\sigma_{\mathrm{n} 0}^{\prime}}\right)^{\mathrm{b}} \leq \mu_{\max } \sigma_{\mathrm{n} 0}^{\prime}$

The excess pore pressure, $\Delta \mathrm{u}_{\max }$, is related to the distance between the initial state and the critical state measured horizontally in the e-ln $\sigma_{n}^{\prime}$ space, which can be viewed as a state parameter, S (see Figure 2b)

$\mathrm{S}=-\ln \left(1-\frac{\Delta \mathrm{u}_{\max }}{\sigma_{\mathrm{n} 0}^{\prime}}\right)$

Using equation (2), the state parameter $\mathrm{S}$ can also be expressed as

$S=\frac{1}{b} \ln \left(\frac{\tau_{d}}{\tau_{u}}\right)$

The parameter $\mathrm{S}$ is also related to the volumetric strain that develops during drained shearing up to the critical state (see Figure 2b)

$\mathrm{S}=\Delta \varepsilon_{\mathrm{v}, \max } \frac{1+\mathrm{e}_{0}}{\lambda}$

For a typical value of pore pressure ratio $\Delta \mathrm{umax}_{\max } / \sigma^{\prime}{ }_{\mathrm{n} 0}=0.5$ the ratio of undrained to drained resistance is about 0.6 and $\mathrm{S}=0.69$.

For the case of an overconsolidated material, the undrained resistance increases as a function of overconsolidation ratio (OCR)

$\tau_{\mathrm{u}}=\left(\tau_{\mathrm{u}}\right)_{\mathrm{NC}} \mathrm{OCR} \mathrm{R}^{\mathrm{b} \cdot \Lambda}$

where $\Lambda=(\lambda-\kappa) / \lambda$ and $\mathrm{k}$ is the slope of the one-dimensional unloading-reloading response in the e-ln $\sigma_{n}^{\prime}$ space. Note that for $b=1$ (i.e. a stress-independent friction angle), equation (6) is 
the classical critical state relationship for soil strength (Schofield \& Wroth, 1968; Wroth, 1984; Wood, 1990), or the SHANSEP equation given by Ladd et al. (1977).

\subsection{Partially drained soil-interface resistance}

\section{Continuous consolidation}

In the case where the velocity of the shearing process is such that some degree of consolidation occurs during shearing up to the residual strength, the interface resistance is controlled by the two processes of generation and dissipation of shear induced excess pore pressure. These coupled processes have been captured in a simplified model of planar shearing by Randolph et al. (2012). The model considers an infinite slab pressing on a soil surface with a pressure, $\sigma^{\prime}{ }_{n}$, moving horizontally with a velocity, $v$. This causes shearing to occur in a shear band of thickness, $\mathrm{h}_{\mathrm{s}}$, resulting in generation of excess pore pressure, $\Delta \mathrm{u}$. Based on the one-dimensional consolidation solution (approximated using parabolic isochrones, e.g., Schofield \& Wroth, 1968) and balance of the water volume flowing out of the shear band and into the soil, the following equation was proposed by Randolph et al. (2012) to describe the pore pressure dissipation during partially drained shearing

$$
\Delta \varepsilon_{\mathrm{v}, \max } \frac{1+\mathrm{e}_{0}}{\lambda}+\ln \left(1-\frac{\Delta \mathrm{u}}{\sigma_{\mathrm{n} 0}^{\prime}}\right)=\frac{\Delta \mathrm{u}}{\sigma_{\mathrm{n} 0}^{\prime}} \sqrt{1.33 \frac{\mathrm{c}_{\mathrm{v}} \mathrm{t}}{\mathrm{h}_{\mathrm{s}}^{2}}}
$$

where $c_{v}$ is the coefficient of consolidation of the soil and $t$ denotes the elapsed time. Note that the first term in equation (7) is equal to the state parameter S defined in equation (3) and shown in Figure $2 b$.

The interface resistance during partially drained shearing is given by equation (2), with the pore pressure $\Delta \mathrm{u}$ obtained as a function of time by solving equation (7). The variation of normalised shearing resistance, or stress ratio $\tau / \sigma^{\prime}{ }_{n}$, with normalised time $T=c_{\mathrm{v}} \mathrm{t} /\left(\mathrm{h}_{\mathrm{s}}\right)^{2}$ is 
shown in Figure 3, for the case of a linear strength model $(b=1$ in equations 1 and 2), a drained friction coefficient $\tau / \sigma_{n}^{\prime}=0.6$ and a state parameter, $S=1$. This response can be approximated by the following equation

$$
\frac{\tau}{\sigma_{\mathrm{n} 0}^{\prime}}=\left(\frac{\tau}{\sigma_{\mathrm{n} 0}^{\prime}}\right)_{\text {drained }}-\left[\left(\frac{\tau}{\sigma_{\mathrm{n} 0}^{\prime}}\right)_{\text {drained }}-\left(\frac{\tau}{\sigma_{\mathrm{n} 0}^{\prime}}\right)_{\text {undrained }}\right] 0.5^{\left(\mathrm{T} / \mathrm{T}_{50}\right)^{\mathrm{n}}}
$$

where $\mathrm{T}_{50}$ is the time at which the normalised resistance is midway between the undrained and drained limits and $\mathrm{n}$ is a constant. Equation (8) is also plotted in Figure 3 (dashed line) for $\mathrm{T}_{50}=3$ and $\mathrm{n}=0.4$

In the case of shearing in the direct shear box, the numerical work by Potts et al. (1987) has shown that localisation of shear strains in a thin band occurs after the peak shear stress has been reached and that a significant increase in shear stress also occurs in soil outside the shear band. In applying the proposed model, we are considering only the post peak conditions and neglecting possible pore pressure generation outside the shear band.

\section{Episodic consolidation}

In some practical cases, the soil-structure interface may be subjected to intermittent displacements that cause undrained shearing of the soil, with intervening consolidation periods. Initial undrained shearing causes excess pore pressure to be generated in the shear zone and a reduction in effective vertical stress, as shown by path $\mathrm{AC}$ in Figure $2 \mathrm{~b}$. During the subsequent consolidation period, the shear zone hardens as the soil contracts and soil elements in the shear zone follow path CD. Undrained shearing from point D causes the hardened shear zone to reach failure at point E, with a higher effective stress and therefore higher shear strength compared to the strength obtained during the initial shearing (path AC). After $\mathrm{N}$ cycles of undrained shearing followed by consolidation the soil-interface undrained resistance is increased due to consolidation hardening and is given by 
$\tau_{\mathrm{uN}}=\tau_{\mathrm{ui}}\left(\mathrm{e}^{\mathrm{s}}\right)^{\mathrm{b}\left(1-\Lambda^{\mathrm{N}}\right)}=\tau_{\mathrm{ui}}\left(\frac{\tau_{\mathrm{d}}}{\tau_{\mathrm{ui}}}\right)^{\left(1-\Lambda^{\mathrm{N}}\right)}$

where $\tau_{u i}$ is the soil-interface undrained resistance during the initial movement of the interface (Hill \& White, 2015). The volumetric strain in the shear layer is given by

$$
\Delta \varepsilon_{\mathrm{v}}=\frac{1}{1+\mathrm{e}_{0}} \sum_{\mathrm{i}=1}^{\mathrm{N}} \kappa \mathrm{S}\left(1-\frac{\kappa}{\lambda}\right)^{\mathrm{i}-1}
$$

and converges towards $\Delta \varepsilon_{\mathrm{v}, \max }=\lambda \mathrm{S} /\left(1+\mathrm{e}_{0}\right)$ as $\mathrm{N}$ increases. This simple model based on a single element being subjected to successive failures matches well with finite element analyses in which the entire zone of soil beneath a pipeline is modelled (Yan et al., 2014) and model tests performed on pipeline elements at large scale (White et al. 2015). This supports the application of this simple 'single element' model to predict episodic pipeline-seabed or foundation-seabed sliding resistance.

The purpose of this paper is to analyse two sets of interface shear box tests data obtained for marine clays and investigate whether the models described above can be applied to describe the observed behaviour.

\section{SOILS, INTERFACES, APPARATUS AND SPECIMEN PREPARATION}

\section{Soil types and interfaces}

Two marine clays were tested, which we denote Soil A and Soil B. The clay samples were provided in $80 \mathrm{~mm}$ diameter Shelby tubes and were remoulded at their natural water content prior to testing. The water content measured after remoulding was $\sim 250 \%$ for Soil $\mathrm{A}$ and $\sim 70 \%$ for Soil B. The two clays have high plasticity, with Atterberg limits as listed in Table 1 . The two interfaces used were made out of three layer polyethylene (3LPE) with different values of roughness to mimic different pipeline coatings. The "rough" interface had a 
roughness, $\mathrm{R}_{\mathrm{a}}>80 \mu \mathrm{m}$, whereas the "smooth" interface had a roughness $\mathrm{R}_{\mathrm{a}} \sim 2 \mu \mathrm{m}$. The interface roughness was measured using a stylus profilometer. The interfaces were fitted into the lower half of the shearbox.

\section{Shear box apparatus}

The interface shear box tests were carried out using the ShearTrac-II-DSS system, developed by Geocomp Corporation (Houston), which can be operated as a simple shear or a direct shear device, via computer control. The ShearTrac II load frame was adapted at UWA to be able to carry tests at low normal stress, by replacing the original vertical loading mechanism with a conventional dead-weight load frame. Episodic tests, which include stages of consolidation between shearing cycles, can be automatically controlled by the computer. The shear stress resulting from the friction between the upper half and lower half of the shear box was measured by performing a test with exactly the same set-up as an actual test, but without a soil specimen in the upper half of the shear box. The results yielded a friction of $0.5 \mathrm{kPa}$, which remained constant for the entire shearing phase. All data collected during testing were corrected by subtracting this value from the measured shear stress.

\section{Specimen preparation}

Testing was conducted on remoulded specimens in order to achieve repeatability and to reproduce the condition of the soil around a pipe after it has been laid on the seabed (the laying process causes significant remoulding and disturbance, Cheuk \& White 2011). Remoulded specimens were prepared according to the following method. A sufficient quantity of soil for the full testing programme was recovered from sample tubes. The soil was remoulded at the natural water content using a mixer, then divided into samples for each test and stored in airtight bags until required. For each test, the required soil was then placed into a ring with diameter and height equal to $72 \mathrm{~mm}$ and $19 \mathrm{~mm}$, respectively. The specimen was 
then transferred to the upper half of the shear box, on top of the interface plate fitted into the lower half of the box. The specimen was consolidated to a specified normal stress. In the case of an overconsolidated specimen, the initial consolidation was followed by unloading to the required normal stress level, and the specimen was allowed to swell prior to the shearing stage.

\section{TESTING METHODOLOGY}

\subsection{Test methodology}

Interface shear box tests consisted of applying shearing cycles of $+/-5 \mathrm{~mm}$ horizontal displacement at a specified displacement rate. Depending on the rate used, two shearing patterns were followed, as described below (Figure 4).

\section{Slow and intermediate shearing}

In slow and intermediate tests, a total of two shearing cycles were applied in order to identify the steady soil-interface resistance (called residual resistance in this paper) mobilized at large displacements. A displacement rate of $0.001 \mathrm{~mm} / \mathrm{s}$ was used for the slow case, which is likely to be drained, whereas displacement rates of 0.01 and $0.03 \mathrm{~mm} / \mathrm{s}$ were applied for the two intermediate cases. After the second shearing cycle was completed, a final horizontal displacement of $10 \mathrm{~mm}$ was imposed.

\section{Fast shearing}

In fast tests, the shearing cycles are applied in pairs, to identify the residual soil-interface resistance, with a period of consolidation between each cycle pair, to evaluate the effect of consolidation hardening. For the fast shearing case, a displacement rate of $0.1 \mathrm{~mm} / \mathrm{s}$ was used, which is likely to be undrained. A total of 20 cycles were applied (10 pairs), with periods of 30 minutes consolidation between each pair. 
Gibson \& Henkel (1954) have proposed an approximate solution to estimate the degree of consolidation at failure, $U_{c}$, during shearing in the direct shear box, assuming the whole sample thickness is sheared in an homogeneous manner. According to this equation, using the consolidation coefficient listed in Table 1 and assuming the residual interface resistance is reached after $40 \mathrm{~mm}$ displacement (see Section 6.2) we predict $\mathrm{U}_{\mathrm{c}}<1 \%$ for the fast rate (i.e., undrained) and $\mathrm{U}_{\mathrm{c}}=72 \%$ for the slow rate (i.e., close to drained).

\subsection{Testing programme}

The testing programme is shown in Table 2. It consists of a series of 12 tests, which were carried out for each of the two soils. The first four tests were slow tests (at a displacement rate of $0.001 \mathrm{~mm} / \mathrm{s}$ ), referred to as drained tests, which investigated the effect of interface roughness and normal stress. Three normal stress levels were considered; a base case value of $4 \mathrm{kPa}$ and lower and higher values of 2 and $8 \mathrm{kPa}$. The same four tests were repeated with a fast rate of shearing $(0.1 \mathrm{~mm} / \mathrm{s})$ in tests 5 to 8 , referred to as undrained tests (later interpretation validates these test labels of drained and undrained). Tests 9 and 10 were conducted at intermediate speeds, whereas tests 11 and 12 were fast tests investigating the effect of OCR.

\section{RESULTS AND DISCUSSION}

\subsection{Consolidation response}

The response during initial consolidation under the applied normal stress is shown in Figure 5 for Soil A. The coefficient of consolidation of the clay, $\mathrm{c}_{\mathrm{v}}$, can be estimated by considering the theoretical one-dimensional consolidation solution for $50 \%$ consolidation (Taylor 1948)

$$
c_{v}=0.196\left(\frac{\mathrm{H}^{2}}{t_{50}}\right)
$$


where $\mathrm{H}$ is the specimen thickness and $\mathrm{t}_{50}$ is the time corresponding to $50 \%$ consolidation. With $\mathrm{H}=19 \mathrm{~mm}$ and $\mathrm{t}_{50} \sim 70 \mathrm{mins}$ and $60 \mathrm{mins}$ for Soil A and B respectively, the consolidation coefficient at low stress is $\mathrm{c}_{\mathrm{v}} \sim 0.5 \mathrm{~m}^{2} /$ year for Soil A and $\mathrm{c}_{\mathrm{v}} \sim 0.6 \mathrm{~m}^{2} /$ year for Soil B (as reported in Table 1). This one-dimensional analysis is approximate for the interface shear box because it neglects the dissipation that may occur via flow through any gap between the shear box and the interface plate. However, the values of $c_{v}$ determined for the two soils are consistent with values of 1.0-2.0 $\mathrm{m}^{2} /$ year which were obtained from oedometer tests for slightly higher stress level ( $\sim 5$ to $30 \mathrm{kPa})$.

\subsection{Drained interface resistance}

A typical response obtained during a drained ISB test carried out at a displacement rate of $0.001 \mathrm{~mm} / \mathrm{s}$ is shown in Figure 6. During shearing, the shear stress increases gradually, until it reaches a steady value at large displacements, termed residual stress in this paper. The drained interface resistance was determined from the residual shear stress measured after 40 $\mathrm{mm}$ displacement ( 2 cycles), with a correction of $-0.5 \mathrm{kPa}$ for box friction. The residual shear stress is plotted as a function of normal stress in Figure 7a. From Figure 7a, it can be seen that the failure envelope exhibits a slight degree of non-linearity and that the data can be reasonably well approximated by equation (1) (curve fitting is based on three data points for each soil and yielded $\mathrm{R}^{2}$ values of 0.96 and 0.99 for Soil A and B, respectively). The values of parameters $\mathrm{a}$ and $\mathrm{b}$ in equation (1) are reported in Table 1 for the two soils. A similar nonlinear drained failure envelope was obtained by Najjar et al. (2007) from tilt table tests on Gulf of Mexico clay as reproduced in Figure $7 b$.

The residual stress ratio, $\tau / \sigma^{\prime}$, is in the range 0.73 to 1 for Soil $A$ and 0.7 to 0.8 for Soil $\mathrm{B}$, and increases by 25 and $15 \%$ as the normal stress decreases from 8 to $2 \mathrm{kPa}$, for Soil $\mathrm{A}$ and $\mathrm{B}$ respectively (Table 3$)$. These results were obtained with the rough interface $\left(\mathrm{R}_{\mathrm{a}}>80 \mu \mathrm{m}\right)$ and 
correspond to drained residual secant friction angles in the range 36 to $45^{\circ}$ for Soil A and 35 to $39^{\circ}$ for Soil B. When compared with the databases reported by Lupini et al. (1981) and Eid et al. (2015) these values are greater than most of the residual friction angles obtained for natural soils and are similar to values measured on residual clayey soils (Wesley 1977). These high shear resistances would typically be associated with a turbulent mode of shear. It is possible that the soils tested would exhibit a lower interface shear resistance at large displacement (hundreds of millimetres), if the particles were platy. However, shearing at large displacement is not easily achieved with the shear box and was not investigated in this study. When using a smooth interface $\left(\mathrm{R}_{\mathrm{a}} \sim 2 \mu \mathrm{m}\right)$, the drained residual friction angle is reduced to $\sim$ $30^{\circ}$ for Soil $\mathrm{A} \sim 20^{\circ}$ for Soil $\mathrm{B}$. This is consistent with the results reported by Lemos and Vaughan (2000) showing that a smooth interface promotes a sliding mode of residual shear, with lower friction angle.

These results are consistent with data reported by Najjar et al. (2007) for clay-interface residual strength measurements carried out using a tilt table for normal stresses in the range 1.7 to $5.8 \mathrm{kPa}$. The failure envelope reported by these authors showed a slight degree of nonlinearity and values of the drained residual friction angle were around $30^{\circ}$ for an interface with $50 \mu \mathrm{m}$ roughness.

\subsection{Undrained interface resistance}

Figure 8 shows an example of the first 2 cycles of the shearing sequence (Figure $4 \mathrm{~b}$ ) applied for undrained ISB tests carried out at a displacement rate of $0.1 \mathrm{~mm} / \mathrm{s}$. The shear stress response exhibits a peak at small displacement $(\sim 1.5 \mathrm{~mm})$, followed by softening until the residual shear stress is reached. The undrained interface resistance was determined from the residual shear stress measured after $40 \mathrm{~mm}$ displacement ( 2 cycles), with a correction of -0.5 $\mathrm{kPa}$ for box friction. The residual stress ratio values obtained for the undrained tests are listed 
in Table 3 (Tests 5, 7 and 8) and are in the range 0.35 to 0.45 for Soil A and 0.33 to 0.36 for

Soil B. These values are smaller than the corresponding drained values by a factor of $\sim 0.47$ (on average, see Table 1).

Using equation (2) for the undrained interface resistance, the pore pressure ratio, $\Delta \mathrm{u}_{\max } / \sigma^{\prime}{ }_{\mathrm{n} 0}$, has been estimated for each undrained test and is equal to $\sim 0.6$ on average for both soils (see Table 1). This leads to a ratio $\left(\sigma^{\prime}{ }_{n 0}-\Delta \mathrm{u}_{\max }\right) / \sigma^{\prime}{ }_{n 0} \sim 0.4$, which is slightly less than the ratio of undrained to drained strength due to the non-linearity of the effective stress failure envelope. The corresponding value of the state parameter, $\mathrm{S}$, determined using equation (3), is listed in Table 1 and is approximately $\mathrm{S} \sim 0.85$. Similarly as for the drained resistance, the undrained interface resistance measured with the smooth interface is smaller than the one obtained with the rough interface (see Tests 5 and 6 in Table 3).

For both soils, an increase in undrained interface resistance with OCR was observed and can be modelled using equation (6) (See Figure 9). From curve fitting of the data plotted in Figure 9 it can be inferred that for Soil $\mathrm{A}, \Lambda=0.68$, whereas for Soil $\mathrm{B}, \Lambda=0.57$ (curve fitting is based on three data points for each soil and yielded $\mathrm{R}^{2}=0.99$ for both Soil). These values fall within the range of values reported for a wide range of clays $(0.5<\Lambda<0.8$, Schofield $\&$ Wroth, 1968).

\subsection{Partially drained interface resistance}

\section{Continuous consolidation}

During ISB tests carried out at intermediate displacement rates, some consolidation takes place during shearing, leading to interface resistance between the undrained and drained values. The residual stress ratio measured during ISB tests carried out at various velocities spanning the range of drained to undrained response is plotted in Figure 10 with respect to the shearing velocities. The data correspond to Tests $2,5,9$ and 10 performed with an initial 
normal effective stress of $4 \mathrm{kPa}$ and can be approximated by an equation with a similar format as equation (8)

$$
\frac{\tau}{\sigma_{\mathrm{n} 0}^{\prime}}=\left(\frac{\tau}{\sigma_{\mathrm{n} 0}^{\prime}}\right)_{\text {drained }}-\left[\left(\frac{\tau}{\sigma_{\mathrm{n} 0}^{\prime}}\right)_{\text {drained }}-\left(\frac{\tau}{\sigma_{\mathrm{n} 0}^{\prime}}\right)_{\text {undrained }}\right] 0.5^{\left(\mathrm{v}_{50} / \mathrm{v}\right)^{\mathrm{n}_{\mathrm{v}}}}
$$

where $\mathrm{v}_{50}$ is the velocity for which the stress ratio is midway between the undrained and drained values and $n_{v}$ is a constant. For Soil A and B the values of v50 are 0.01 and 0.006 $\mathrm{mm} / \mathrm{s}$ respectively and $\mathrm{n}_{\mathrm{v}}=1.5$.

The interface resistance data are plotted again in Figure 11 with respect to normalised time $\mathrm{T}$ $=\mathrm{c}_{\mathrm{v}} \mathrm{t} /\left(\mathrm{h}_{\mathrm{s}}\right)^{2}$, where $\mathrm{t}$ is the time corresponding to $40 \mathrm{~mm}$ shearing displacement (2 cycles), when the residual stress is measured. The $c_{v}$ values for each clay, estimated from the consolidation response, are listed in Table 1 . The shear band thickness, $\mathrm{h}_{\mathrm{s}}$, is chosen such that the data corresponding to midrange between the drained and undrained value matches the prediction from the planar shearing model of Randolph et al. (2012). This leads to values of $h_{s}$ $=5 \mathrm{~mm}$ for Soil $\mathrm{A}$ and $\mathrm{h}_{\mathrm{s}}=6 \mathrm{~mm}$ for Soil $\mathrm{B}$. The prediction from the planar shearing model plotted in Figure 11 was obtained using the drained friction coefficient and the value of $\mathrm{S}$ determined for $\sigma^{\prime}{ }_{n}=4 \mathrm{kPa}$ (See Table 1), and the value of the failure envelope exponent, $\mathrm{b}$, listed in Table 1 for each soil. Figure 11 also shows the model approximation given by equation ( 8 ) for $\mathrm{T}_{50}=3$ and $\mathrm{n}=0.35$ for both soils. It appears that the data exhibit a faster transition from undrained to drained response in comparison with the planar shearing model and that a value of $n=1.5$ should be used in equation (8) to capture the observed behaviour.

The more rapid drainage may be due to flow occurring at the base perimeter of the sample, with water escaping between the upper and lower half of the shear box. In this case, the flow can be described by the solution for radial flow in an infinite cylinder with uniform initial pore pressure and zero pore pressure at the surface of the cylinder, as given by Carslaw \& 
Jaeger (1959) for the flow of heat. This solution provides the average pore pressure in a cylinder of radius $\mathrm{R}$ as

$$
\Delta \mathrm{u}_{\mathrm{av}}=4 \Delta \mathrm{u}_{\max } \sum_{\mathrm{i}=1}^{\infty} \frac{1}{\beta_{\mathrm{i}}^{2}} \mathrm{e}^{-\mathrm{T}^{*} \beta_{\mathrm{i}}^{2}}
$$

where $\Delta \mathrm{u}_{\max }$ is the pore pressure generated during undrained shearing to the critical state, $\mathrm{T}^{*}$ is the dimensionless time defined as $T^{*}=c_{v} t / R^{2}$ and $\beta_{i}$ are the roots of $J_{0}(\beta)=0$, with $J_{0}$ the Bessel function of order 0 (the six first roots are given by Carslaw \& Jaeger 1959). Figure 12 shows the interface resistance calculated using equations (13) and (2) as a function of dimensionless time $\mathrm{T}^{*}$, together with the test data. The dimensionless time $\mathrm{T}^{*}$ was calculated using the specimen radius, $\mathrm{R}=36 \mathrm{~mm}$, and the values of $\mathrm{c}_{\mathrm{v}}$ listed in Table 1 .

The agreement between model and data is reasonably good, showing that the radial flow solution captures adequately the transition from undrained to drained regime. Therefore, the radial flow solution (Equation (13)) can be used to estimate the $c_{v}$ value of soils tested in ISB tests. As an extension to the above discussion, in the case of pipe-soil interface, it is expected that some flow will occur along the circumferential direction of the pipe up to the free surface of the soil. This is supported by some preliminary study of the flow pattern around a pipeline reported by Carneiro et al. (2015), for the simplified case of a pipe embedded in a linear poroelastic half space and subjected to a vertical load. This study shows that the flow pattern around the pipe invert changes with dimensionless time, evolving from outward radial flow (away from the pipe), to circumferential flow and then inward radial flow (towards the pipe).

\section{Episodic consolidation}

The process of consolidation hardening, which takes place during periods of rest between intermittent shearing events, was simulated using ISB tests with the shearing sequence shown in Figure 4b. An example of results obtained during this process is illustrated in Figure 13. 
Figure 13a shows the results for the fast test, Test 5, on Soil A. During this test, the sample was allowed to consolidate for 30 minutes after each pair of fast shearing cycles, leading to hardening of the clay as the water content decreased. The shape of the consolidation curves recorded during the 30 minutes period seems to indicate that the soil had reached a degree of consolidation between 70 and $90 \%$ in all cases. The resulting increase in shear stress during subsequent undrained shearing is clearly visible in Figure 13a. The undrained interface resistance measured at the end of the fast test, after nine periods of consolidation, is close to the drained resistance measured in the drained test (Figure 13b). This suggests that apart from consolidation effects, the application of previous shearing events does not affect the drained resistance over the displacement range tested.

As described in Section 3, the increase in undrained interface resistance due to cycles of consolidation hardening can be modelled using equation (9). Figures 14 shows a comparison of the measured data and the model prediction given by equation (9). The parameters used in equation (9) were determined previously from the drained and undrained resistance, as well as the results on overconsolidated soil, and are listed in Table 1. The point shown at the origin of the plot corresponds to the shear stress measured at the end of the first two shearing cycles $\left(\tau_{\mathrm{ui}}\right)$ and subsequent data points are obtained after $\mathrm{N}$ consolidation cycles. For Soil A, a very good agreement between the data for the test at $4 \mathrm{kPa}$ normal stress and the model is obtained (Figure 14a). After five consolidation cycles, the residual shear stress stabilises to a final value, which is slightly lower than the drained residual strength. The data for the test at $8 \mathrm{kPa}$ normal stress show a lower resistance compared to the model prediction. This may be attributed partly to the soil not reaching full consolidation during the 30 minutes period. For Soil B, the model prediction is acceptable (Figure 14b). However, the resistance measured for the test at $4 \mathrm{kPa}$ normal stress increases above the drained residual value after five consolidation cycles. It is possible that some error in shear stress measurement may have been 
caused by some accumulated misalignment in the shear box, leading to additional frictional resistance.

The volumetric strain in the shear layer accumulated after $\mathrm{N}$ cycles of shearing and consolidation can be described using Equation (10). The prediction from Equation (10) is compared with experimental measurements for two tests on Soil A in Figure 15. The values of the parameters $S, \lambda$ and $\kappa$ are listed in Table 1. Determination of $\lambda$ is discussed in the next section and $\kappa$ is deduced from $\lambda$ and $\Lambda$ (See Table 1). Specimen vertical settlement is measured during ISB test and to convert this measurement into volumetric strain, the thickness of the shear layer is required. The data plotted in Figure 15 was calculated by assuming a shear layer thickness of $5 \mathrm{~mm}$, in order to obtain a reasonable match with the model prediction for the initial part of the curve. After four consolidation cycles, the volumetric strain increases above the model prediction. This may be due to pore pressure dissipation from soil that is away from the interface shearing zone and is subjected to cycles of shear stress, causing some level of excess pore pressure to be generated and subsequently dissipated. Further detailed studies of the kinematics within an interface shear test and the spatial variation in moisture content would be required to shed light on these details.

\subsection{Discussion on critical state model parameters}

The models discussed in Section 3 are based on the critical state framework. They assume that initial states obtained from one-dimensional compression of the soil can be represented by a straight line in the e-ln $\sigma_{n}^{\prime}$ space, the NCL. Shearing from these initial states brings the state of the soil to a residual state that lies on the CSL (Figure 2). Both the NCL and the CSL have a slope defined by the parameter $\lambda$, and the distance between the two lines measured horizontally is given by the parameter S (equation 3). In this section, we use the data from the 
ISB tests to estimate the critical state model parameters defining the NCL, and the CSL for both soils and discuss the findings.

Figure 16 shows the data points corresponding to the state of the specimens at the end of consolidation under a normal stress of 2, 4 and $8 \mathrm{kPa}$ (Tests 1, 3, 4, 5, 7 and 8) plotted in e-ln $\sigma^{\prime}{ }_{n}$ space. The void ratio at the end of consolidation was calculated using the initial water content measured before the test and the vertical settlement measured during consolidation, adopting a soil specific gravity of $\mathrm{G}_{\mathrm{s}}=2.7$. Figure 16 indicates that the data can be reasonably well fitted by a straight line, the NCL, with the best fit parameters yielding a slope $\lambda=0.64$ for Soil A and $\lambda=0.12$ for Soil B. The latter value of $\lambda$ falls within the range of typical values observed for a wide range of clays (Schofield \& Wroth, 1968). However, Soil A, which has a high liquidity index (LI 3.9), exhibits a relatively high compressibility (high $\lambda$ ). This is consistent with data reported by Hong et al. (2010) for reconstituted clays, which show that the slope $\lambda$ increases as the water content increases above the liquid limit (data show slope as high as $\lambda \sim 0.6$ in the low stress range). The consolidation data plotted in Figure 16 exhibits more scatter in the low stress range, where measurement error becomes significant in interpretation of the measured vertical settlement.

The CSL was estimated from the drained residual states reached during the slow ISB test (Tests 2, 3 and 4). The void ratio at the residual state was calculated in two ways: (i) from the volumetric strain, obtained by dividing the vertical settlement measured after $40 \mathrm{~mm}$ shearing ( 2 cycles) by the specimen height at the start of shearing, (ii) from the water content at the end of the test (with $\mathrm{G}_{\mathrm{s}}=2.7$ ). Figure 16 shows that the CSL has a similar slope, $\lambda$, as the NCL, consistent with conventional critical state theory and that the two methods of estimating the void ratio at the critical state yield reasonably close results for Soil A (there is some scatter in the results for Soil B). Also plotted in Figure 16 is the final state of the specimens subjected to 
cyclic shearing with episodes of consolidation. In this case, the total vertical settlement measured during the consolidation periods is used to compute the volumetric strain and the final void ratio, which is also determined from the final water content at the end of the test. No data point is shown for Tests 5 and 8 on Soil B, as error in measurement lead to negligible values of vertical settlement. From Figure 16 it can be seen that the critical state reached at the end of the cyclic tests with episodic consolidation agrees reasonably well with that obtained from the drained tests. Again, more scatter is observed at low normal stress.

The estimation of the critical states discussed above assumes that the whole specimen is subjected to shearing and volume change due to consolidation. This is consistent with the finite element analysis of the direct shear box reported by Potts et al. (1987), which shows that close to failure, almost the entirety of the specimen is subjected to high shear stress ( $>90 \%$ of the strength mobilised at the central shear plane). This assumption is also supported by the volumetric strain measurements shown in Figure 15, which seem to indicate that soil outside the layer of shearing at the interface is contributing to the consolidation settlement.

From the plots of Figure 16, the value of the state parameter, $\mathrm{S}$, was determined as $\mathrm{S}=0.82$ for Soil $\mathrm{A}$ and $\mathrm{S}=0.84$ for Soil $\mathrm{B}$. These values are very similar and correspond to a ratio $\mathrm{r}_{\mathrm{u}}=$ $\sigma^{\prime}{ }_{n 0} / \sigma_{n u}^{\prime} \sim 2.30$, where $\sigma^{\prime}{ }_{n u}$ is the effective normal stress reached at the critical state during undrained shearing. This ratio is slightly larger than the ratio predicted by the original Camclay model (Roscoe \& Schofield, 1963, Schofield \& Wroth, 1968), $r_{u}=e^{\Lambda}$, which gives the values $r_{u}=2.0$ for Soil A and $r_{u}=1.8$ for Soil B (using the values of $\Lambda$ listed in Table 1 ). The ratio predicted by the modified Cam-clay model (Roscoe \& Burland, 1968) is $r_{u}=2^{\Lambda}$, and yields the values $r_{u}=1.5$ for Soil $A$ and $r_{u}=1.6$ for Soil $B$, which again are smaller than the measured values. 
This suggests that the effective stress paths followed by Soil A and B during undrained ISB test differ from that predicted by the Cam-clay models. In fact, the undrained response of Soil A and B exhibits a peak in shear stress followed by softening (See Figure 8), which cannot be modelled using the standard Cam-clay models and a normally-consolidated initial state. During softening, additional excess pore pressure is generated, causing the stress path to track to a lower effective stress level and therefore a lower shear stress after failure is reached. This is consistent with the effective stress paths identified in undrained interface shear tests that include internal pore pressure measurements, reported by Tsubakihara \& Kishida (1993).

The value of the parameter S determined from the NCL and CSL in the e-ln $\sigma_{n}^{\prime}$ can be used to estimate the resistance ratio $\tau_{\mathrm{u}} / \tau_{\mathrm{d}}$ using equation (4). The predicted values are $\tau_{\mathrm{u}} / \tau_{\mathrm{d}}=0.50$ for Soil $A$ and $\tau_{\mathrm{u}} / \tau_{\mathrm{d}}=0.47$ and compare reasonably well with the measured values reported in Table 1.

\section{CONCLUDING REMARKS}

A series of interface shear box (ISB) tests conducted on two marine clays have demonstrated the influence on the measured soil-interface shear resistance of normal stress level, overconsolidation ratio, interface roughness and drainage - both during and in between shearing episodes. The high interface resistance (friction angle $>35^{\circ}$ ) measured at the shearing displacements achieved in the ISB suggests a turbulent mode of shear and the conclusions given below apply to that case. The drained failure envelope in the normal stress range between 2 and $8 \mathrm{kPa}$ was found to be slightly non-linear, leading to increases in resistance (as measured by the stress ratio $\tau / \sigma^{\prime}$ no) by 15 to $25 \%$ as the normal stress decreases from 8 to 2 $\mathrm{kPa}$. The effect of OCR in the low OCR range $(\mathrm{OCR} \leq 3)$ was well captured by a power law model similar to that proposed in the critical state framework. Using a smooth interface $\left(\mathrm{R}_{\mathrm{a}} \sim\right.$ 
$2 \mu \mathrm{m})$ results in a lower soil-interface resistance compared to the rough interface $\left(\mathrm{R}_{\mathrm{a}}>80 \mu \mathrm{m}\right)$, with the decrease in resistance varying with the soil type.

The effect of partial drainage and consolidation was investigated for two types of scenario; one where partial consolidation occurs during continuous shearing, and the other one where episodes of undrained shearing are interspersed with periods of consolidation. For the case of consolidation during continuous shearing, it was found that the solution for consolidation during planar shearing at the boundary of an infinite soil body was not directly applicable to ISB tests, due to drainage allowed to take place between the upper and lower half of the shear box. The solution for radial dissipation of excess pore pressure at the base of the specimen leads to a reasonable prediction of the transition from undrained to drained regime as a function of dimensionless time, with the characteristic length being the radius of the sample. This solution provides a means of interpreting ISB tests to determine the coefficient of consolidation, $\mathrm{c}_{\mathrm{v}}$, of the soil tested. For the case of episodic shearing and consolidation, a simple critical state framework is shown to capture well the changing interface strength with consolidation cycles, allowing ISB tests to be interpreted in a consistent framework - deriving critical state-type strength parameters - for application in design. Comparison of predicted and measured volumetric strain is less successful due to soil outside the initial shear layer contributing to the shearing and consolidation process.

There remains some uncertainty on the volume of soil within the ISB that is involved in the shearing process, and further research investigating the spatial variation in excess pore pressure, changes in moisture content and micro-structure during shearing of soil along an interface is recommended. 


\section{ACKNOWLEDGEMENTS}

The research presented here forms part of the activities of the Centre for Offshore Foundation Systems (COFS), currently supported as a node of the Australian Research Council Centre of Excellence for Geotechnical Science and Engineering (grant CE110001009) and through the Fugro Chair in Geotechnics, the Lloyd's Register Foundation Chair and Centre of Excellence in Offshore Foundations and the Shell EMI Chair in Offshore Engineering, which is held by the second author. The authors would like to thank Andy Hill, from BP, for supporting this work.

\section{NOTATION}

a coefficient for drained shear strength

b exponent for drained shear strength

$\mathrm{c}_{\mathrm{v}}$ consolidation coefficient

CSL critical state line

$\mathrm{e}_{0} \quad$ initial void ratio

$\Delta \mathrm{e}_{\max }$ maximum change in void ratio

$\mathrm{G}_{\mathrm{s}} \quad$ specific gravity

$\mathrm{H}$ height of soil specimen

$\mathrm{h}_{\mathrm{s}} \quad$ shear band thickness

LL liquid limit

LI liquidity index

$\mathrm{n}$ exponent in interface resistance as a function of dimensionless time

$\mathrm{n}_{\mathrm{v}}$ exponent in interface resistance as a function of velocity

$\mathrm{N}$ number of consolidation cycles (i.e., undrained shearing followed by consolidation)

NCL normal compression line

OCR over consolidation ratio 
PL plastic limit

$\mathrm{R}_{\mathrm{a}}$ interface roughness

$r_{u}$ effective normal stress ratio $\sigma_{n 0}^{\prime} / \sigma_{n u}^{\prime}$

S state parameter

t Time

$t_{50}$ time for $50 \%$ consolidation

$\mathrm{T}$ non-dimensional time for planar shearing model

$\mathrm{T}_{50}$ non-dimensional time for $50 \%$ consolidation

$\mathrm{T}^{*}$ non-dimensional time for radial flow model

$\Delta \mathrm{u}_{\max } \quad$ maximum excess pore pressure

$\Delta \mathrm{u}_{\mathrm{av}} \quad$ average excess pore pressure

$\mathrm{U}_{\mathrm{c}}$ Degree of consolidation

v shearing velocity

$\mathrm{V}_{50}$ shearing velocity corresponding to strength midway between undrained and drained values

$\beta_{i}$ roots of $J_{0}(\beta)=0$, where $J_{0}$ is the Bessel function of order 0

$\Delta \varepsilon_{\mathrm{v}, \max } \quad$ maximum volumetric strain

$\Delta \varepsilon_{\mathrm{v}} \quad$ volumetric strain

$\kappa \quad$ slope of elastic compression line

$\lambda$ slope of NCL and CSL

$\Lambda$ exponent for effect of OCR on undrained shear strength

$\mu_{\max }$ maximum value of residual friction ratio

$\sigma_{n}^{\prime} \quad$ effective normal stress

$\sigma_{n 0}^{\prime} \quad$ initial effective normal stress at the start of shearing

$\sigma_{\text {nu }}^{\prime}$ effective normal stress at the critical state during undrained shearing

$\tau$ shear stress

$\tau_{\mathrm{d}}$ drained soil-interface resistance 


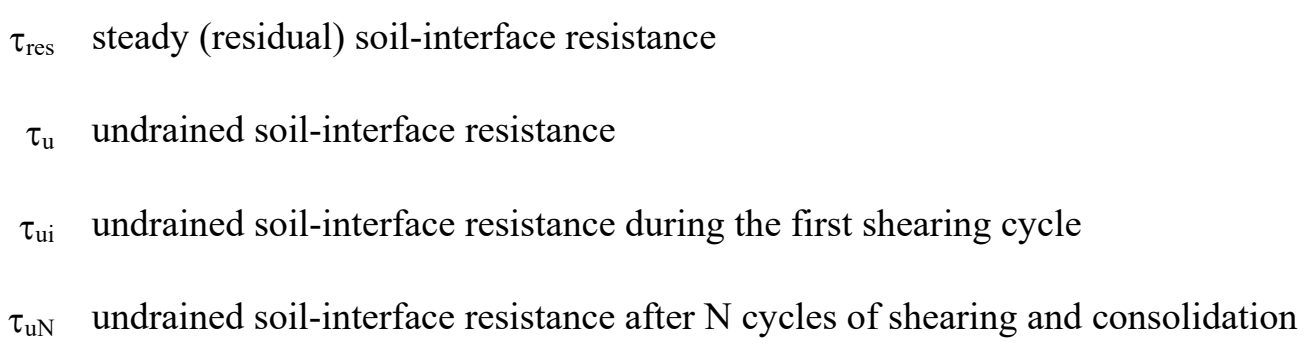

\section{REFERENCES}

Carneiro, D., White, D, J., Danziger, F. A. B. \& Ellwanger, G. B. (2015). Excess pore pressure redistribution beneath pipelines: FEA investigation and effects on pie-soil interaction. Proc. $3^{\text {rd }}$ Int. Symp. on Frontiers in Offshore Geotechnics, Oslo.

Carslaw, H. S. \& Jaeger, J. C. (1959). Conduction of heat in solids. Oxford University Press, Oxford.

Cheuk, C.Y. \& White D.J. (2011). Modelling the dynamic embedment of seabed pipelines. Géotechnique 61, No. 11, 39-57.

Cocjin, M. L., Gourvenec, S. M., White, D.J. \& Randolph, M. F. (2014). Tolerably mobile subsea foundations - observations of performance. Géotechnique 64, No. 11, 895-909.

Corfdir, A., Lerat, P. \& Vardoulakis, I. (2004). A cylinder shear apparatus. Geotech. Testing J. 27, No. 5, DOI: 10.1520/GTJ11551.

Dietz, M. (2000). Developing an holistic understanding of interface friction using sand within the direct shear apparatus. PhD thesis, The University of Bristol.

Eid, H. T., Amarasinghe, R. S., Rabie, K. H. \& Wijewickreme, D. (2014). Residual shear strength of fine-grained soils and soil-solid interfaces at low effective stresses. Can. Geotech. J. 52, No. 2, 198-210. 
Fearon, R. E., Chandler, R. J. \& Bommer, J. J. (2004). An investigation of the mechanisms which control soil behaviour at fast rates of displacement. Advances in geotechnical engineering: The Skempton conference, London, UK: Thomas Telford.

Ganesan, S., Kuo, M. \& Bolton, M. (2014). Influences on pipeline interface friction measured in direct shear tests. Geotech. Testing J. 37, No. 1, DOI: 10.1520/GTJ20130008.

Gibson, R. E., Henkel, D. J. (1954). Influence of duration of tests at constant rate of strain on measured "drained strength". Géotechnique 4, No. 1, 6-15.

Hill, A. J., White, D. J., Bruton, D. A. S., Langford T., Meyer, V., Jewell, R. \& Ballard J.-C. (2012). A new framework for axial pipe-soil interaction illustrated by a range of marine clay datasets. Proc. Int. Conf. on Offshore Site Investigation and Geotechnics. SUT, London.

Hill, A. J. \& White, D. J. (2015). Pipe-soil interaction: recent and future improvements in practice. Proc. $3^{\text {rd }}$ Int. Symp. on Frontiers in Offshore Geotechnics, Oslo.

Ho, T. Y. K., Jardine, R. J. \& Anh-Minh, N. (2011). Large-displacement interface shear between steel and granular media. Géotechnique 61, No. 3, 221-234.

Hong, Z.-S., Yin, J. \& Cui, Y.-J. (2010). Compression behaviour of reconstituted soils at high initial water contents. Géotechnique 60, No. 9, 691-700.

Jardine, R., Chow, F., Overy, R. \& Standing, J. (2005). ICP design methods for driven piles in sands and clays. London, UK: Thomas Telford. 
Ladd, C. C., Foot, R., Ishihara, K., Schlosser, F. \& Poulos, H. G. (1977). Stress-deformation and strength characteristics. Proc. 9th Int. Conf. Soil Mech. Found. Eng., Tokyo, 2, $421-494$.

Lehane, B. M. \& Jardine, R. J. (1992). Residual strength characteristics of Bothkennar clay. Géotechnique 42, No. 2, 363-367.

Lehane, B. M. \& Liu, Q. B. (2013). Measurement of shearing characteristics of granular materials at low stress levels in a shear box. Geotech. Geol. Eng. 31, 329-336.

Lemos, L. J. L. \& Vaughan, P. R. (2000). Clay-interface shear resistance. Géotechnique 50, No. $1,55-64$

Lupini, J. F., Skinner, A. E. \& Vaughan, P. R. (1981). The drained residual strength of cohesive soils. Géotechnique 31, No. 2, 181-213.

Najjar, S. S., Gilbert, R. B., Liedtke, E., McCarron, B. \& Young, A. G. (2007). Residual shear strength for interfaces between pipelines and clays at low effective stresses. ASCE $J$. Geotech. Geoenv. Eng. 133, 695-706.

Pedersen, R. C., Olson, R. E. \& Rauch, A. F. (2003). Shear and interface strength of clay at very low effective stress. Geotech. Testing J. 26, No. 1, 71-77.

Potts, D. M., Dounias, G. T. \& Vaughan, P. R. (1987). Finite element analysis of the direct shear box test. Géotechnique 37, No. 1, 11-23.

Potyondy, J. G. (1961). Skin friction between various soils and construction materials. Géotechnique 11, No. 4, 339-353. 
Ramsey, N., Jardine, R., Lehane, B. \& Ridley, A. (1998). A review of soil-steel interface testing with the ring shear apparatus. Proc. Int. Conf. on Offshore Site Investigation and Foundation Behaviour. '98: 'New Frontiers'.

Randolph, M. F., White, D. J. \& Yan, Y. (2012). Modelling the axial resistance on deep-water pipelines. Géotechnique 62, No. 9, 837-846.

Roscoe, K. H. \& Schofiled, A. N. (1963). Mechanical behaviour of an idealised wet clay. Proc. $2^{\text {nd }}$ European Conf. Soil Mech., 47-54.

Roscoe, K. H. \& Burland, J. B. (1968). On the generalised stress-strain behaviour of 'wet' clay. In Engineering plasticity, Cambridge University Press, 535-609.

Schofield, A. N. \& Wroth, C. P. (1968). Critical state soil mechanics. Blackie Academic, Glasgow.

Skempton, A. W. (1985). Residual strength of clays in landslides, folded strata and the laboratory. Géotechnique 35, No. 1, 3-18.

Stark, T. D. \& Eid, H. T. (1994). Drained residual strength of cohesive soils. ASCE J. Geotech. Eng. 120, No. 5, 856-871.

Taylor, D. W. (1948). Fundamentals of Soil Mechanics, Wiley, New York.

Tika, T. E., Vaughan, P. R. \& Lemos, L. J. L. (1996). Fast shearing of pre-existing shear zones in soil. Géotechnique 46, No. 2, 197-233. 
Tsubakihara Y. and Kishida H. 1993. Frictional behaviour between normally consolidated clay and steel by two direct shear type apparatuses. Soils and Foundations 33, No.2, 113.

Wesley, L. D. (1977). Shear strength propertiesof halloysite and allophane clays in Java, Indonesia. Geotechnique 27, No. 2, 125-136.

White, D.J., Campbell, M.E., Boylan, N.P. \& Bransby, M. F. (2012). A new framework for axial pipe-soil interaction illustrated by shear box tests on carbonate soils. Proc. Int. Conf. on Offshore Site Investigation and Geotechnics. SUT, London.

White D.J., Leckie, S.H.F., Draper, S., Zakarian, E. (2015). Temporal changes in pipelineseabed condition and their effect on operating behaviour. Proc. Int. Conf. Offshore Mech. and Arctic Engng. OMAE2015-42216

Wijewickreme, D., Amarasinghe, R. \& Eid, H. (2014). Macro-scale direct shear test device for assessing soil-solid interface friction under low effective normal stresses. Geotech. Testing J. 37, No. 1, DOI: 10.1520/GTJ20120217.

Wood. D.M. (1990). Soil behaviour and critical state soil mechanics. Cambridge University Press, Cambridge.

Wroth, C.P. (1984). The interpretation of in situ soil tests. Géotechnique 34, No. 4, 449-489.

Yan, Y., White D.J. \& Randolph M.F. (2014). Cyclic consolidation and axial friction on seabed pipelines Géotechnique Letters 4:165-169. 
Yoshimi, Y. \& Kishida, T. (1981). A ring torsion apparatus for evaluating friction between soil and metal surfaces. Geotech. Testing J. 4, No. 4, 145-152. 
Table 1. Summary of soil parameters

\begin{tabular}{|c|c|c|c|}
\hline Description & Parameter & Soil A & Soil B \\
\hline Liquid limit & LL $(\%)$ & 129 & 110 \\
\hline Plasticity Index & PI (\%) & 42 & 63 \\
\hline Consolidation coefficient & $\mathrm{c}_{\mathrm{v}}\left(\mathrm{m}^{2} /\right.$ year $)$ & 0.5 & 0.6 \\
\hline Drained failure envelope coefficient & $\mathrm{a}(\mathrm{kPa})^{(1-b)}$ & 1.04 & 0.87 \\
\hline Drained failure envelope exponent & $\mathrm{b}$ & 0.84 & 0.9 \\
\hline Exponent for OCR effect on undrained strength & $\Lambda$ & 0.68 & 0.57 \\
\hline \multirow[t]{2}{*}{ Ratio undrained/drained resistance ${ }^{*}$} & $\tau_{\mathrm{u}} / \tau_{\mathrm{d}}$ & 0.45 & 0.44 \\
\hline & & 0.52 & 0.42 \\
\hline & & & \\
\hline \multirow[t]{3}{*}{ Pore pressure ratio* } & $\Delta \mathrm{u}_{\max } / \sigma_{\mathrm{n} 0}^{\prime}$ & 0.58 & 0.6 \\
\hline & & 0.61 & 0.6 \\
\hline & & 0.59 & 0.5 \\
\hline \multirow[t]{3}{*}{ State parameter* } & $\mathrm{S}$ & 0.95 & 0.92 \\
\hline & & 0.78 & 0.97 \\
\hline & & 0.98 & 0.73 \\
\hline Slope of normal compression line & $\lambda$ & 0.64 & 0.12 \\
\hline Slope of elastic compression line & $\kappa$ & 0.20 & 0.05 \\
\hline
\end{tabular}

${ }^{*}$ Note: the three values are for $\sigma^{\prime}{ }_{n}=2,4$ and $8 \mathrm{kPa}$, respectively 
Table 2. Testing programme

\begin{tabular}{|c|c|c|c|c|c|c|}
\hline $\begin{array}{l}\text { Test } \\
\text { no. }\end{array}$ & $\begin{array}{l}\text { Inter- } \\
\text { face }\end{array}$ & $\begin{array}{l}\text { Consolidation } \\
\text { stress, } \sigma_{\mathrm{nc}}^{\prime} \\
(\mathrm{kPa})\end{array}$ & $\begin{array}{c}\text { Normal } \\
\text { stress, } \sigma_{\mathrm{n} 0}^{\prime} \\
(\mathrm{kPa})\end{array}$ & $\begin{array}{l}\text { Velocity } \\
(\mathrm{mm} / \mathrm{s})\end{array}$ & $\begin{array}{l}\text { No. of } \\
\text { cycles }\end{array}$ & Description \\
\hline 1 & $\mathrm{R}$ & 4 & 4 & \multirow{4}{*}{0.001} & 2 & Slow base case (SBC) \\
\hline 2 & $\mathrm{~S}$ & 4 & 4 & & 2 & SBC with reduced roughness \\
\hline 3 & \multirow{3}{*}{$\mathrm{R}$} & 8 & 8 & & 2 & SBC at higher stress \\
\hline 4 & & 2 & 2 & & 2 & SBC at lower stress \\
\hline 5 & & 4 & 4 & \multirow{4}{*}{0.1} & 20 & Fast base case (FBC) \\
\hline 6 & $\mathrm{~S}$ & 4 & 4 & & 20 & FBC with reduced roughness \\
\hline 7 & \multirow{6}{*}{$\mathrm{R}$} & 8 & 8 & & 20 & FBC at higher stress \\
\hline 8 & & 2 & 2 & & 20 & FBC at lower stress \\
\hline 9 & & 4 & 4 & 0.03 & 2 & Intermediate base case \\
\hline 10 & & 4 & 4 & 0.01 & 2 & Intermediate base case \\
\hline 11 & & 8 & 4 & 0.1 & 20 & $\mathrm{FBC}$ at $\mathrm{OCR}=2$ \\
\hline 12 & & 12 & 4 & 0.1 & 20 & $\mathrm{FBC}$ at $\mathrm{OCR}=3$ \\
\hline
\end{tabular}

Note: R: Rough with roughness $\mathrm{R}_{\mathrm{a}}>80 \mu \mathrm{m}, \mathrm{S}$ : Smooth with roughness $\mathrm{R}_{\mathrm{a}}=1.94 \mu \mathrm{m}$ 
Table 3. Summary of test results

\begin{tabular}{|c|c|c|c|c|c|c|c|c|c|}
\hline \multirow[b]{2}{*}{$\begin{array}{l}\text { Test } \\
\text { no. }\end{array}$} & \multirow[b]{2}{*}{$\begin{array}{l}\text { Inter- } \\
\text { face }\end{array}$} & \multirow[b]{2}{*}{$\begin{array}{l}\sigma_{\mathrm{n} 0}^{\prime} \\
(\mathrm{kPa})\end{array}$} & \multirow[b]{2}{*}{$\begin{array}{c}\text { Velocity } \\
(\mathrm{mm} / \mathrm{s})\end{array}$} & \multicolumn{3}{|c|}{ Soil A } & \multicolumn{3}{|c|}{ Soil B } \\
\hline & & & & $\begin{array}{l}\text { Peak } \\
\tau_{\mathrm{p}} / \sigma_{\mathrm{n} 0}^{\prime}\end{array}$ & $\begin{array}{c}\text { Residual }^{\mathrm{a}} \\
\tau_{\mathrm{res}} / \sigma_{\mathrm{n} 0}^{\prime}\end{array}$ & $\begin{array}{c}\text { Residual }^{\mathrm{b}} \\
\tau_{\mathrm{res}} / \sigma_{\mathrm{n} 0}^{\prime}\end{array}$ & $\begin{array}{l}\text { Peak } \\
\tau_{\mathrm{p}} / \sigma_{\mathrm{n} 0}^{\prime}\end{array}$ & $\begin{array}{c}\text { Residual }^{\mathrm{a}} \\
\tau_{\mathrm{res}} / \sigma_{\mathrm{n} 0}^{\prime}\end{array}$ & $\begin{array}{c}\text { Residual }^{\mathrm{b}} \\
\tau_{\text {res }} / \sigma_{\text {n0 }}^{\prime}\end{array}$ \\
\hline 1 & 2 & 3 & 4 & 5 & 6 & 7 & 8 & 9 & 10 \\
\hline 1 & $\mathrm{R}$ & 4 & \multirow{4}{*}{0.001} & $\mathrm{~N} / \mathrm{A}$ & 0.73 & $\mathrm{~N} / \mathrm{A}$ & 1.00 & 0.78 & $\mathrm{~N} / \mathrm{A}$ \\
\hline 2 & $\mathrm{~S}$ & 4 & & 0.6 & 0.55 & N/A & 0.50 & 0.35 & N/A \\
\hline 3 & \multirow{3}{*}{$\mathrm{R}$} & 8 & & $\mathrm{~N} / \mathrm{A}$ & 0.80 & N/A & N/A & 0.70 & N/A \\
\hline 4 & & 2 & & $\mathrm{~N} / \mathrm{A}$ & 1.00 & N/A & 1.10 & 0.80 & N/A \\
\hline 5 & & 4 & \multirow{4}{*}{0.1} & 0.78 & 0.38 & 0.78 & 0.75 & 0.32 & 1.03 \\
\hline 6 & $\mathrm{~S}$ & 4 & & 0.78 & 0.35 & 0.65 & 0.30 & 0.15 & 0.15 \\
\hline 7 & \multirow{6}{*}{$\mathrm{R}$} & 8 & & 0.61 & 0.35 & 0.74 & 0.66 & 0.36 & 0.70 \\
\hline 8 & & 2 & & 0.80 & 0.45 & 0.95 & 0.95 & 0.35 & 0.45 \\
\hline 9 & & 4 & 0.03 & 0.73 & 0.40 & N/A & 0.70 & 0.38 & $\mathrm{~N} / \mathrm{A}$ \\
\hline 10 & & 4 & 0.01 & 0.65 & 0.58 & N/A & 0.45 & 0.43 & N/A \\
\hline 11 & & $4^{*}$ & 0.1 & 1.18 & 0.55 & 0.73 & 1.75 & 0.45 & 0.33 \\
\hline 12 & & $4^{* *}$ & 0.1 & 1.35 & 0.70 & 0.80 & 1.60 & 0.58 & 0.30 \\
\hline
\end{tabular}

Note: R: Rough with roughness $\mathrm{R}_{\mathrm{a}}>80 \mu \mathrm{m}, \mathrm{S}$ : Smooth with roughness $\mathrm{R}_{\mathrm{a}}=1.94 \mu \mathrm{m}$

${ }^{a}$ at the end of the first cycle pair

$\mathrm{b}$ at the end of the last cycle after episodic consolidation

* consolidated under $8 \mathrm{kPa}$ and unloaded to $4 \mathrm{kPa}(\mathrm{OCR}=2)$

** consolidated under $12 \mathrm{kPa}$ and unloaded to $4 \mathrm{kPa}(\mathrm{OCR}=3)$ 


\section{LIST OF FIGURES}

Figure 1: Mechanisms controlling axial pipe-soil resistance

Figure 2: Stress paths: (a) $\tau-\sigma_{\mathrm{n}}^{\prime}$ space, (b) e- $\ln \sigma_{\mathrm{n}}^{\prime}$ space

Figure 3: Variation in resistance with time during planar shearing

Figure 4: Shearing patterns: (a) slow and intermediate tests, (b) fast tests

Figure 5: Consolidation response of soil A (Test 5)

Figure 6: Response of Soil A during drained interface shear (Test 3, $\sigma^{\prime}{ }_{n}=8 \mathrm{kPa}$ ): (a) shear stress vs horizontal displacement, (b) Absolute value of shear stress vs cumulative displacement

Figure 7: Drained interface resistance and failure envelope

Figure 8: Response of Soil A during undrained interface shear (Test 7, $\sigma^{\prime}{ }_{n 0}=8 \mathrm{kPa}$ ): (a) shear stress vs horizontal displacement, (b) Absolute value of shear stress vs cumulative displacement

Figure 9: Effect of OCR on undrained interface resistance

Figure 10: Variation in interface resistance with velocity: (a) Soil A, (b) Soil B

Figure 11: Variation in interface resistance with dimensionless time $\mathrm{T}=\mathrm{c}_{\mathrm{v}} \mathrm{t} /\left(\mathrm{h}_{\mathrm{s}}\right)^{2}$ : (a) Soil A, (b) Soil B

Figure 12: Variation in interface resistance with dimensionless time $T^{*}=c_{v} t / R^{2}$ : (a) Soil A, (b) Soil B

Figure 13: Consolidation hardening for Soil A: (a) Fast test (Test 5), (b) comparison of final cycle of fast test and slow test (Test 1)

Figure 14: Normalised resistance vs consolidation cycle number for fast episodic tests: (a) Soil A, (b) Soil B

Figure 15: Volumetric strain vs consolidation cycle number for fast episodic tests on Soil A.

Figure 16: Normal compression line and critical state line: (a) Soil A, (b) Soil B 


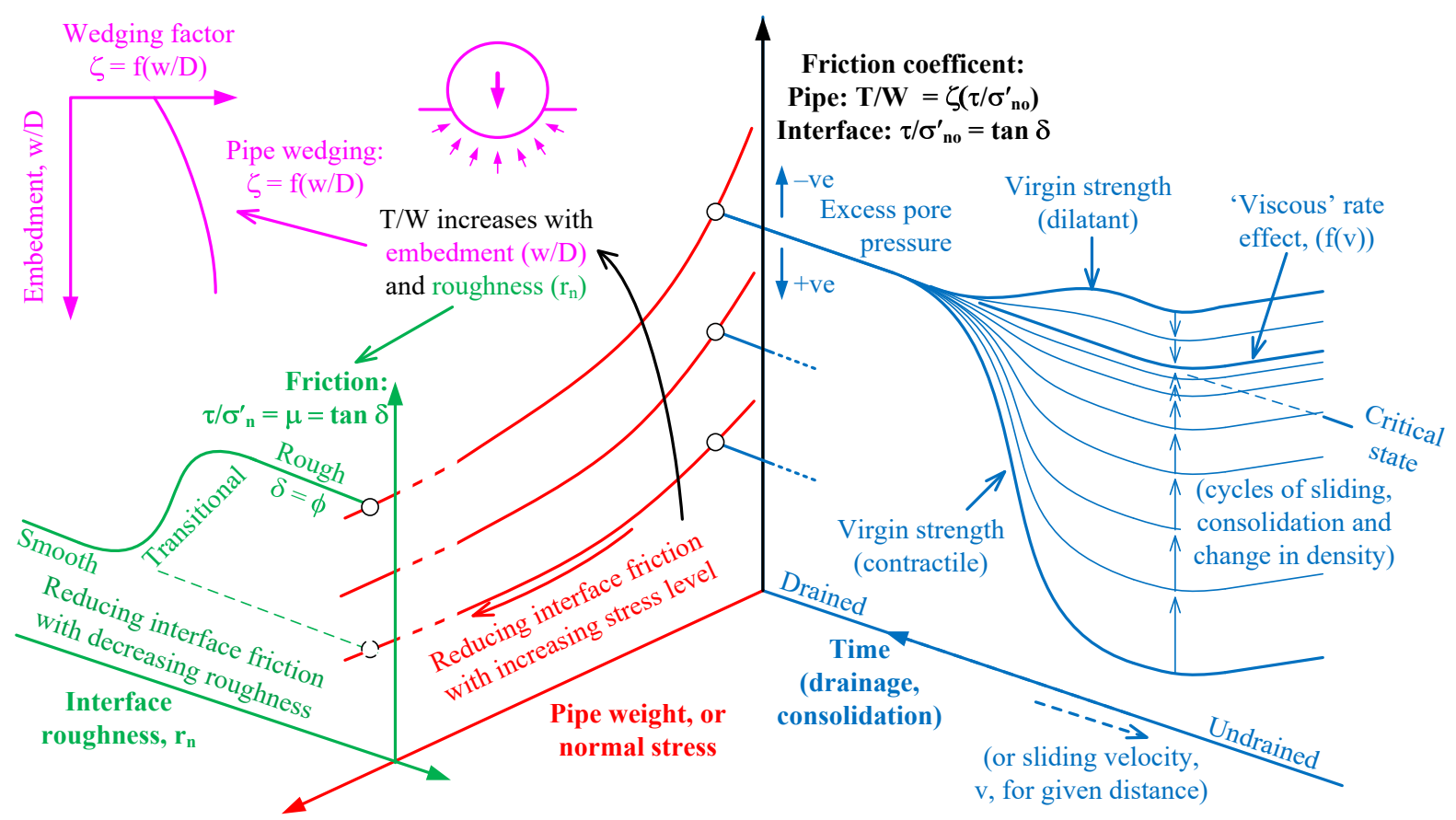

Figure 1: Mechanisms controlling axial pipe-soil resistance (modified from Hill et al. 2012)

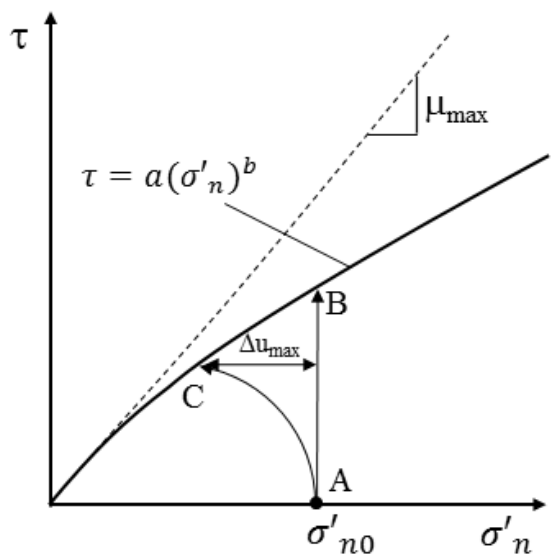

(a)

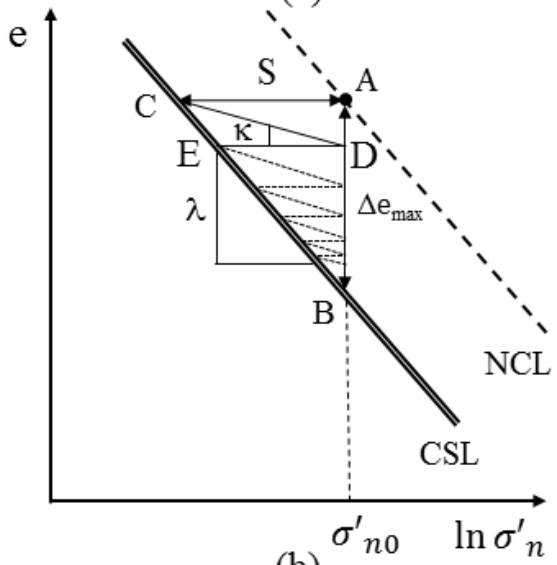

(b)

Figure 2: Stress paths: (a) $\tau-\sigma_{\mathrm{n}}^{\prime}$ space, (b) e- $\ln \sigma_{\mathrm{n}}^{\prime}$ space 


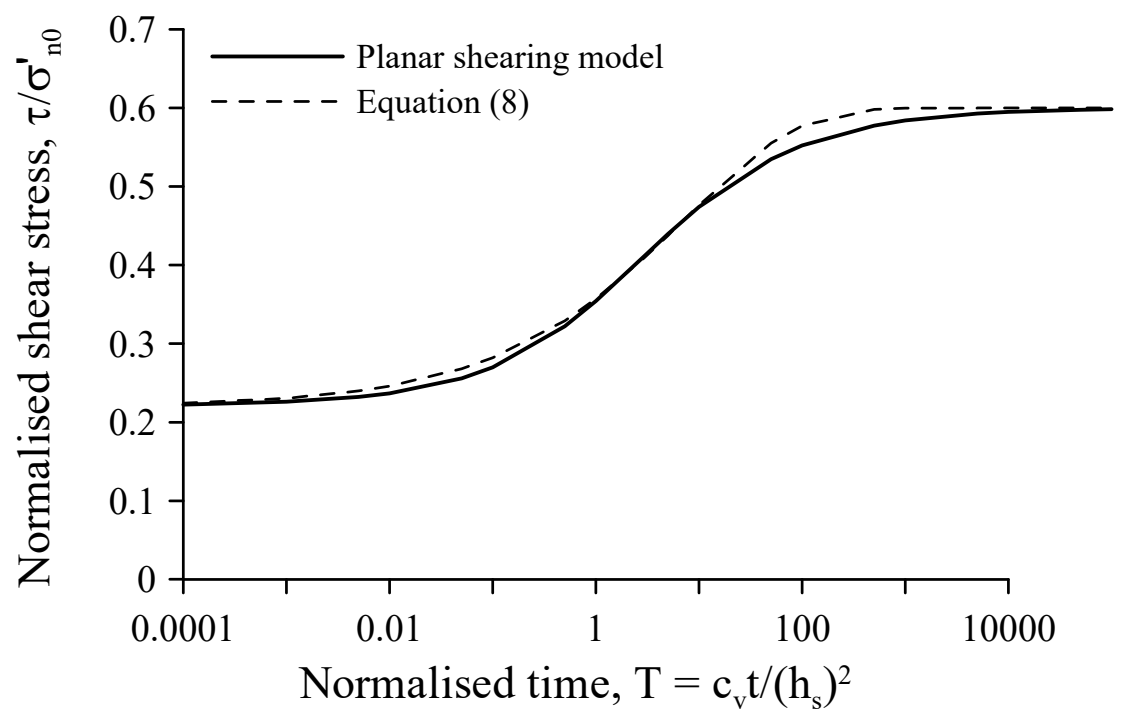

Figure 3 Variation in resistance with time during planar shearing

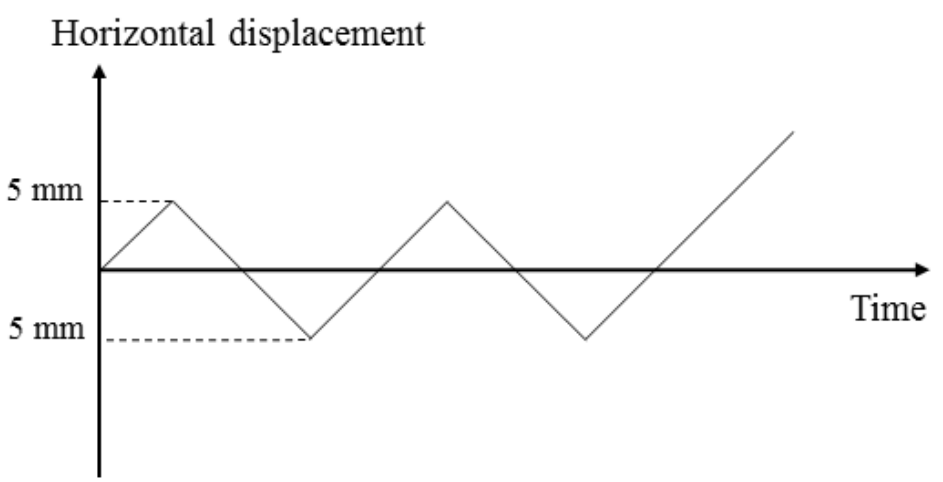

(a)

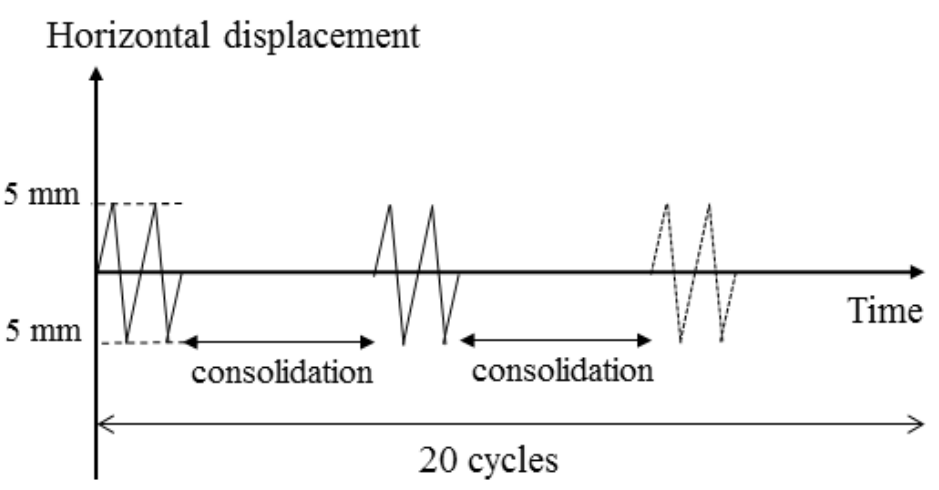

(b)

Figure 4: Shearing patterns: (a) slow and intermediate tests, (b) fast tests 


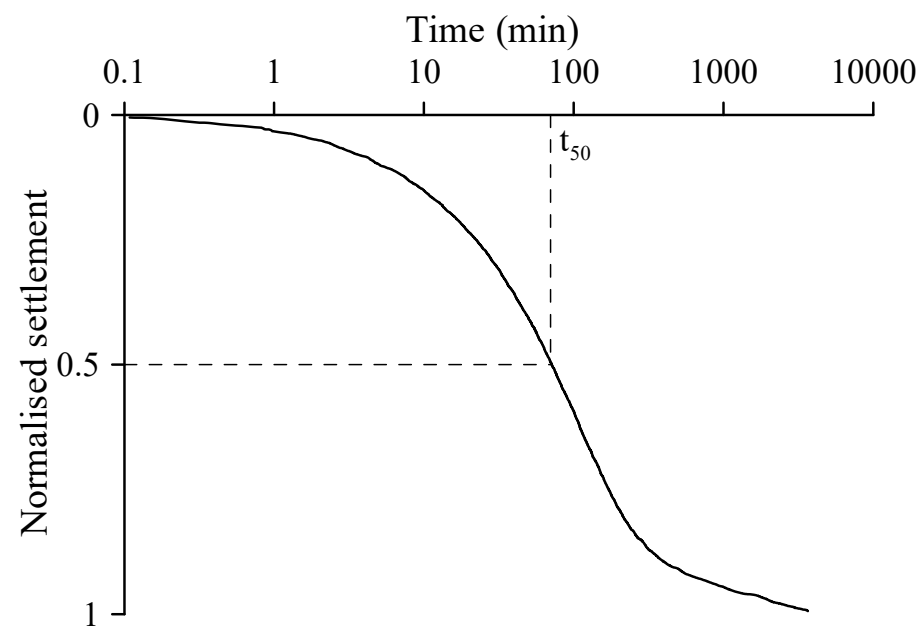

Figure 5: Consolidation response of Soil A (Test 5) 


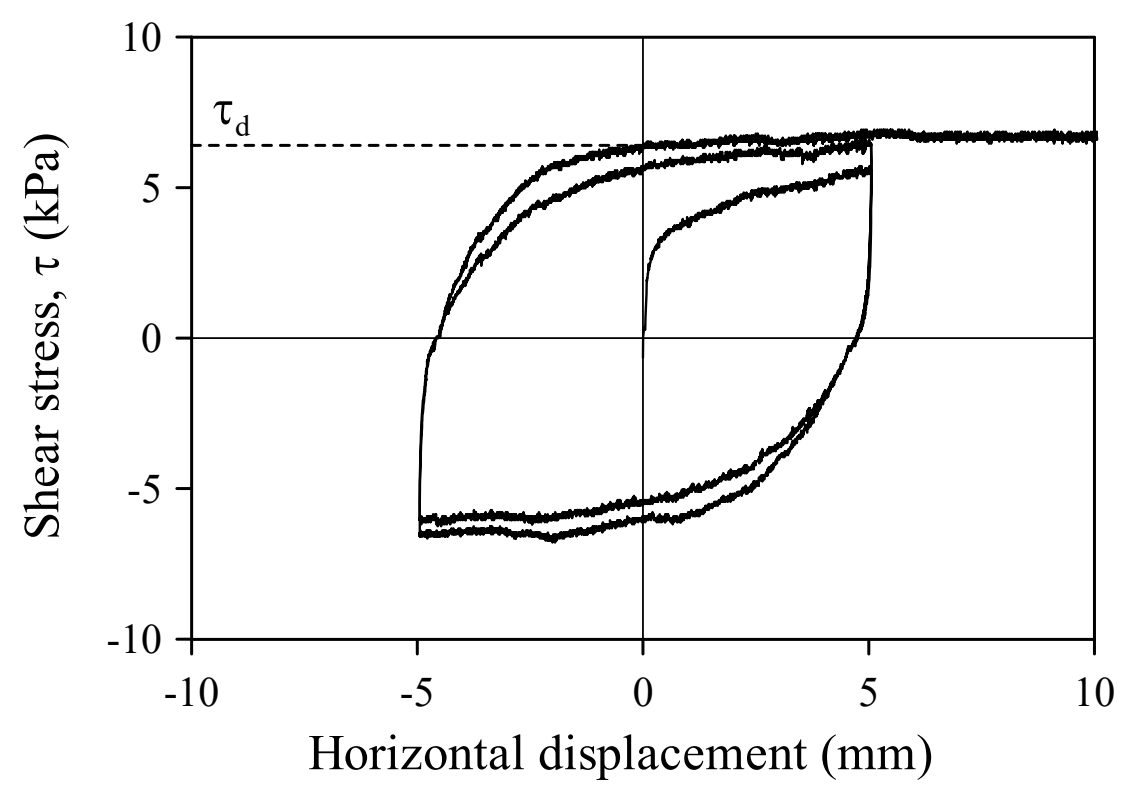

(a)

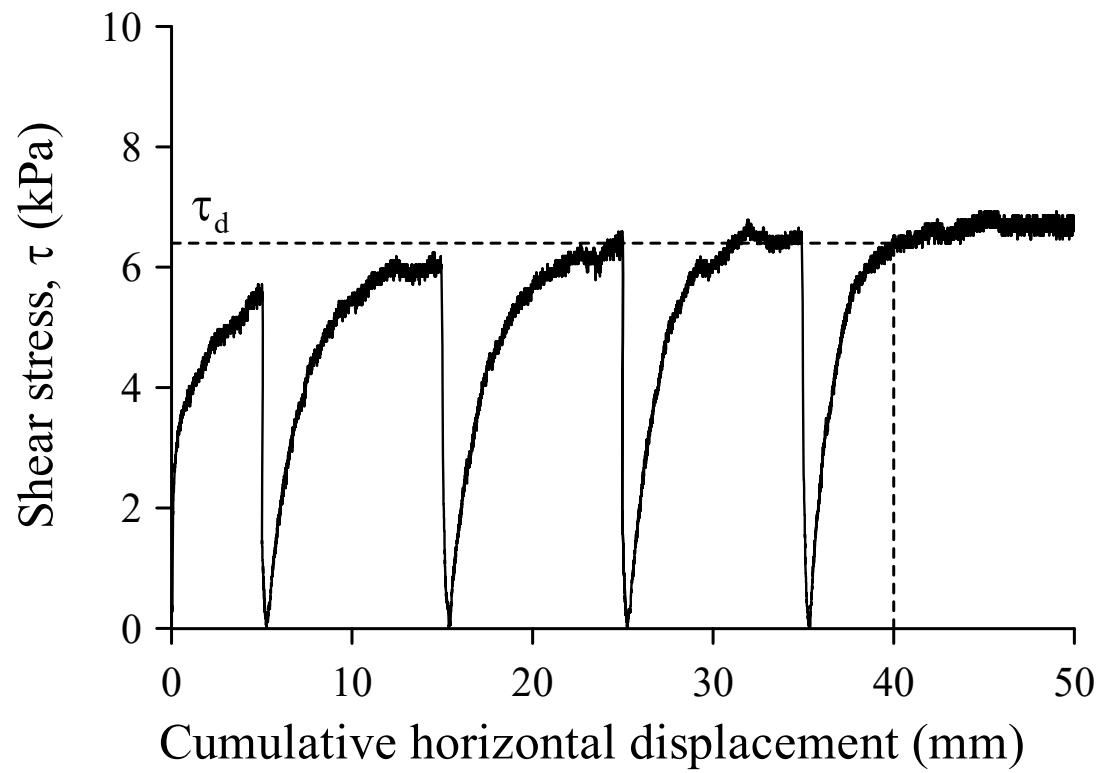

(b)

Figure 6: Response of Soil A during drained interface shear (Test 3, $\sigma^{\prime}{ }_{n 0}=8 \mathrm{kPa}$ ): (a) shear stress vs horizontal displacement, (b) Absolute value of shear stress vs cumulative displacement 


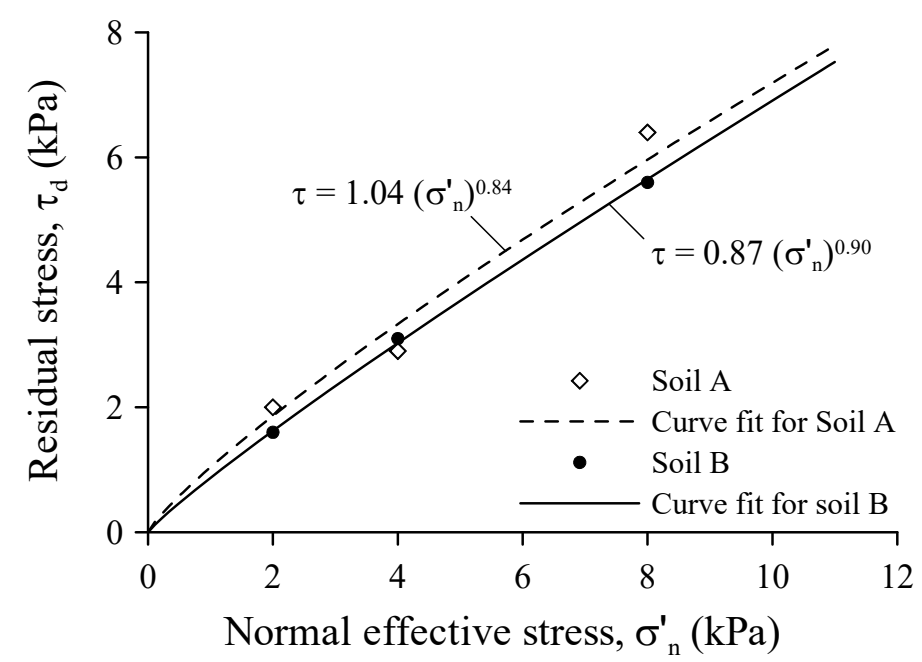

(a)

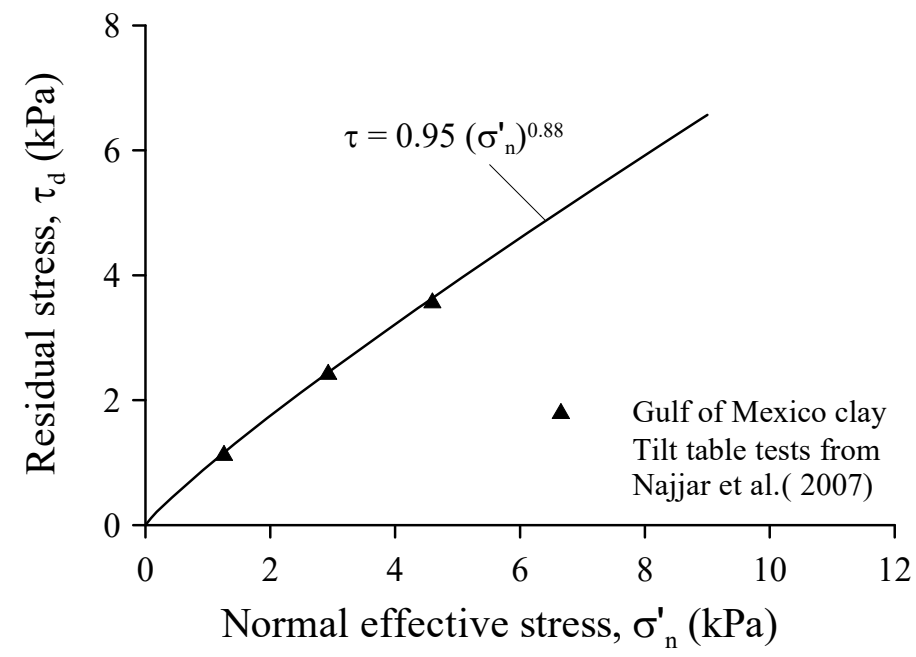

(b)

Figure 7: Failure envelope: (a) drained interface resistance for Soil A and B, (b) drained shear strength of Gulf of Mexico clay (from Najjar et al. 2007) 


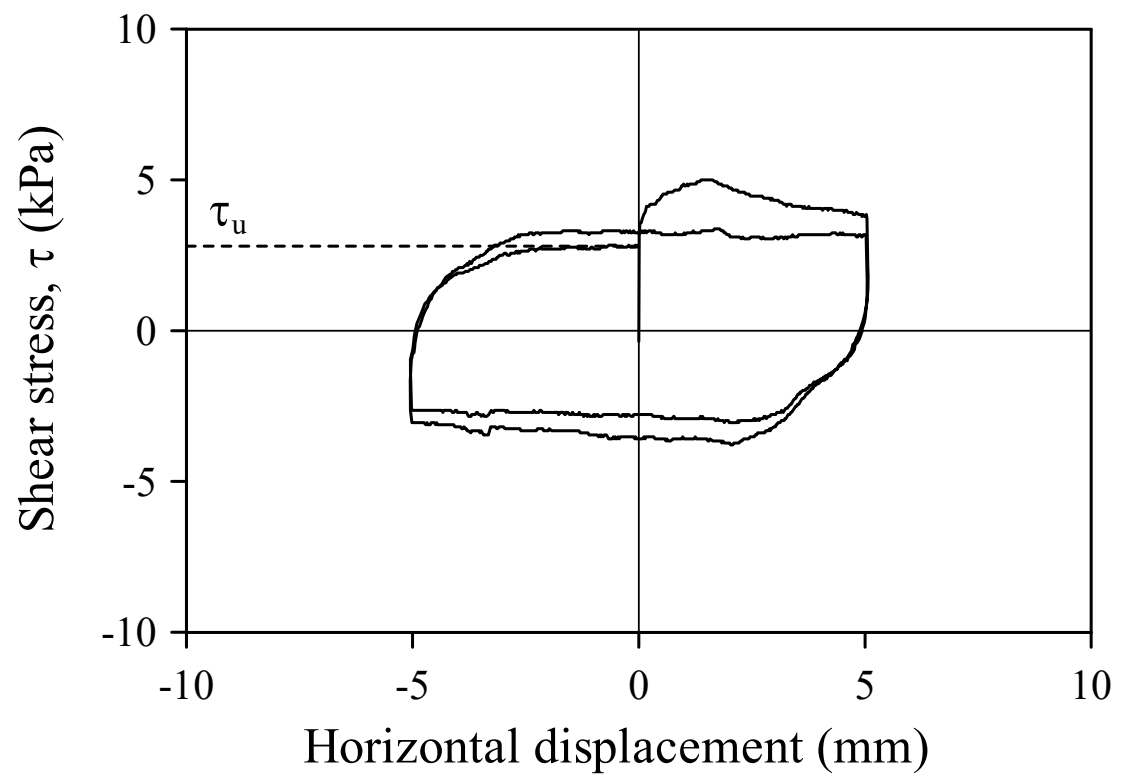

(a)

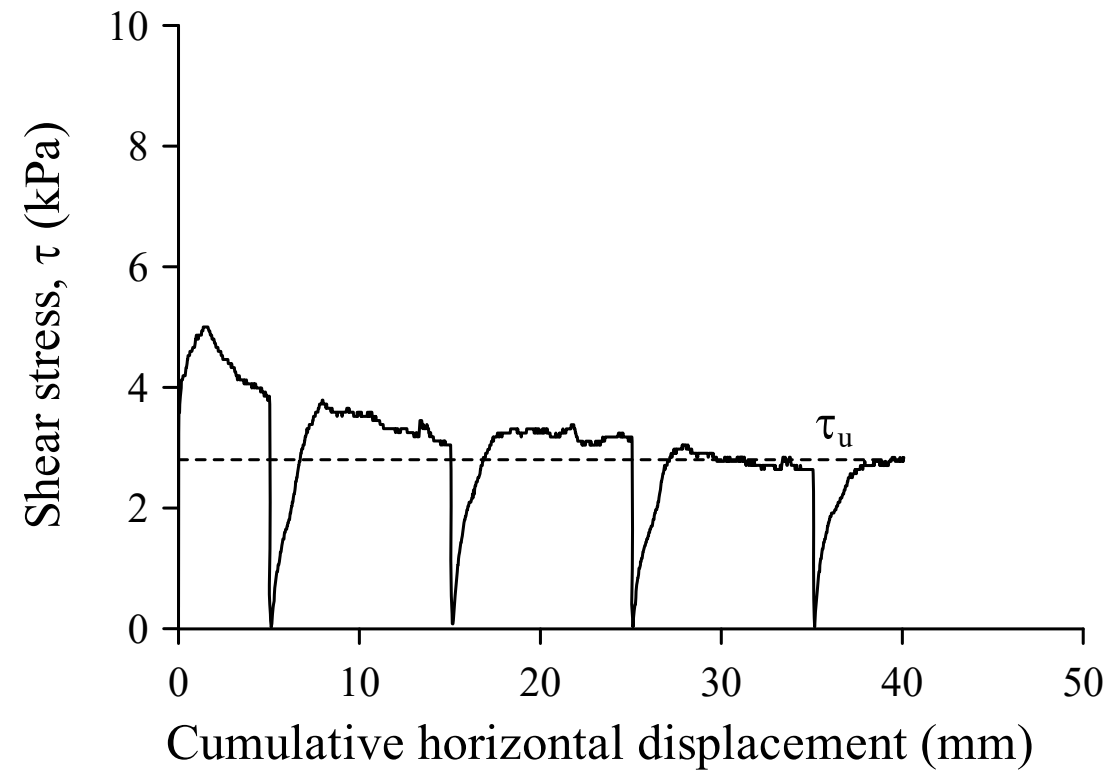

(b)

Figure 8: Response of Soil A during undrained interface shear (Test 7, $\sigma^{\prime}{ }_{n 0}=8 \mathrm{kPa}$ ): (a) shear stress vs horizontal displacement, (b) Absolute value of shear stress vs cumulative displacement 


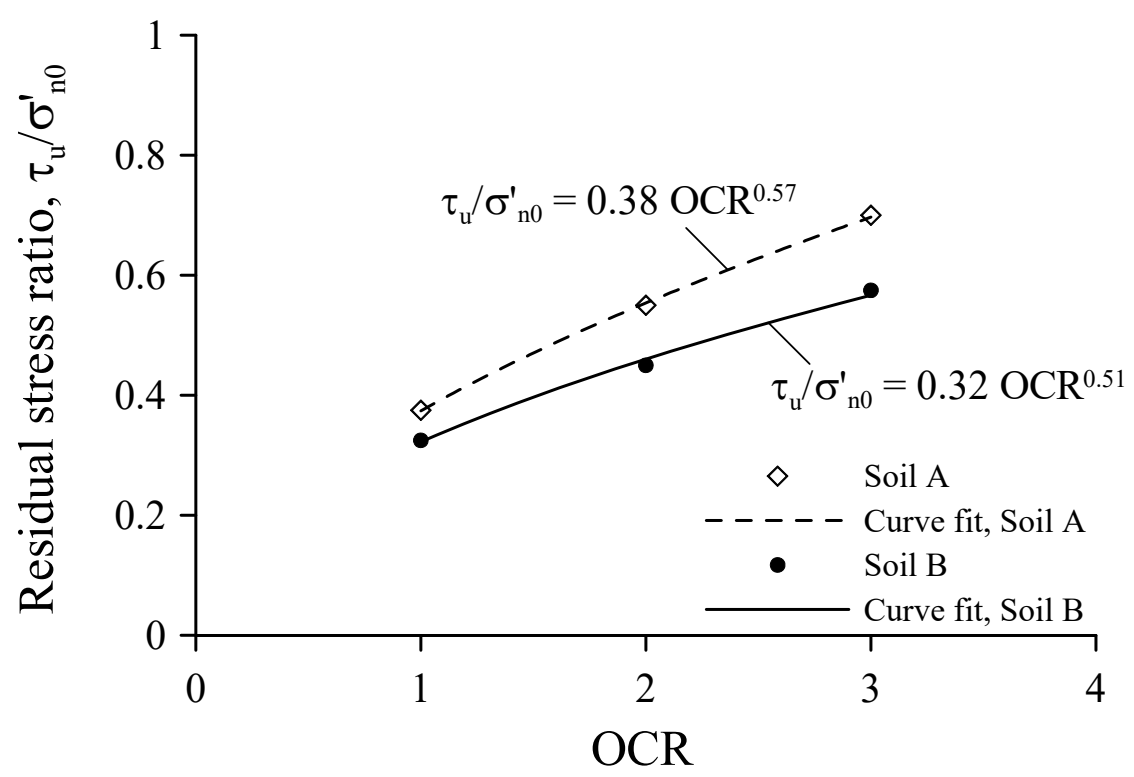

Figure 9: Effect of OCR on undrained interface resistance 


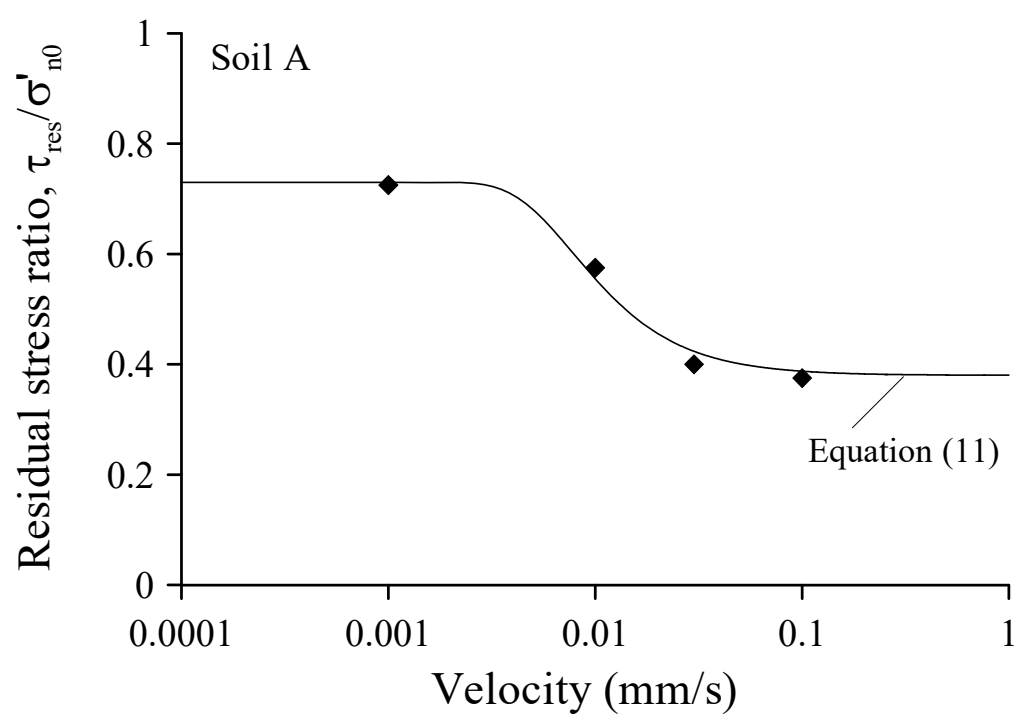

(a)

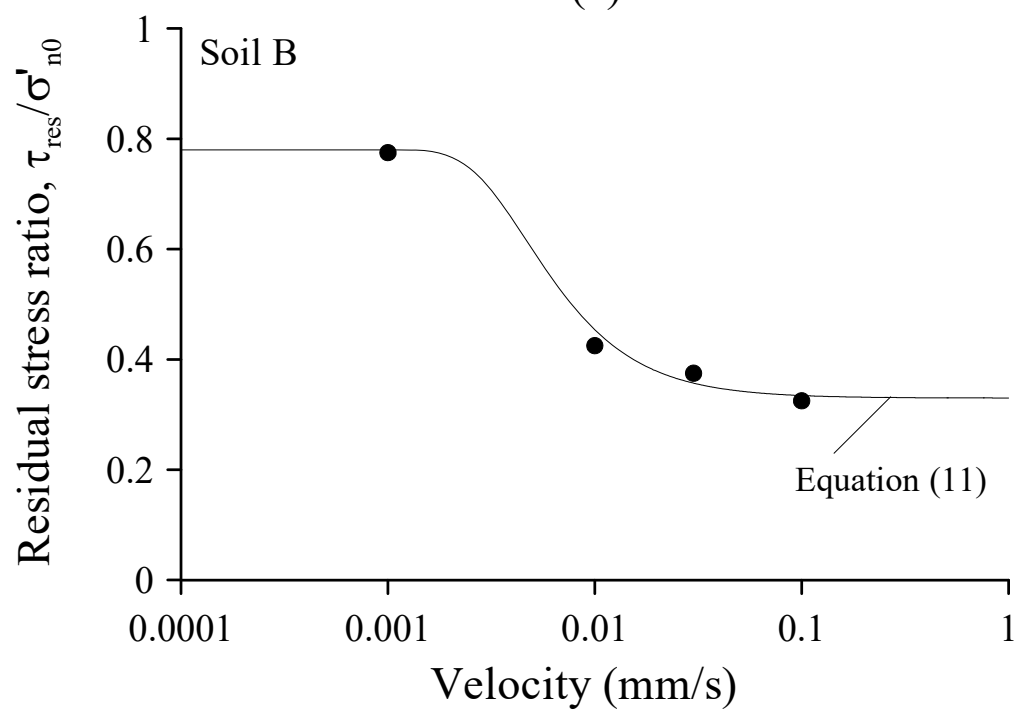

(b)

Figure 10: Variation in interface resistance with velocity: (a) Soil A, (b) Soil B 


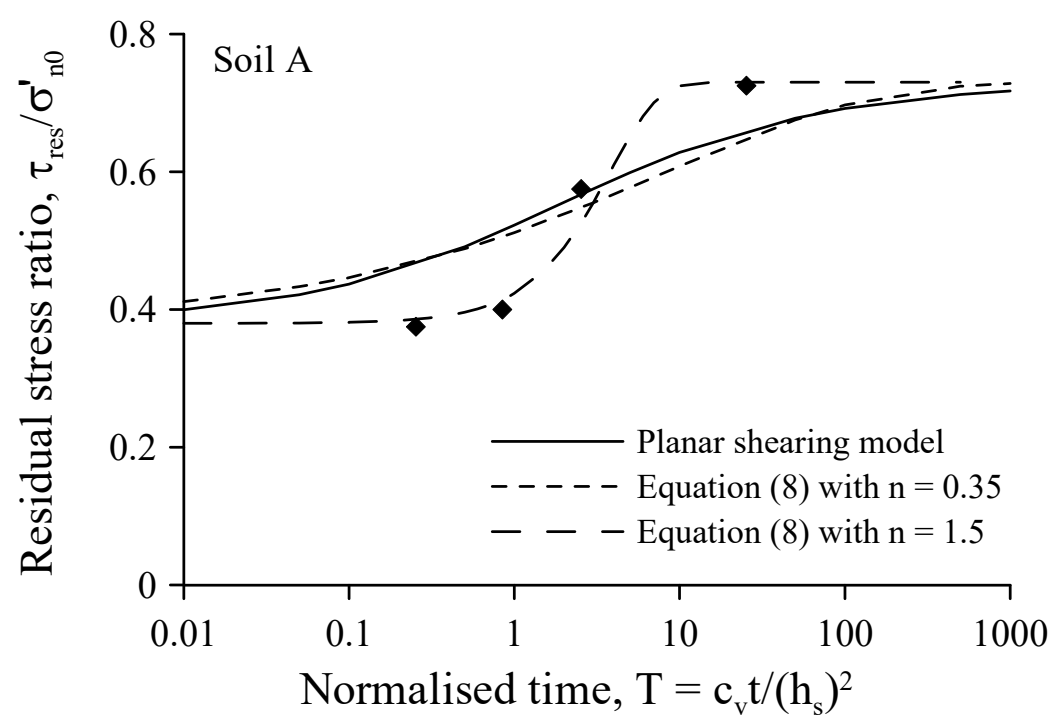

(a)

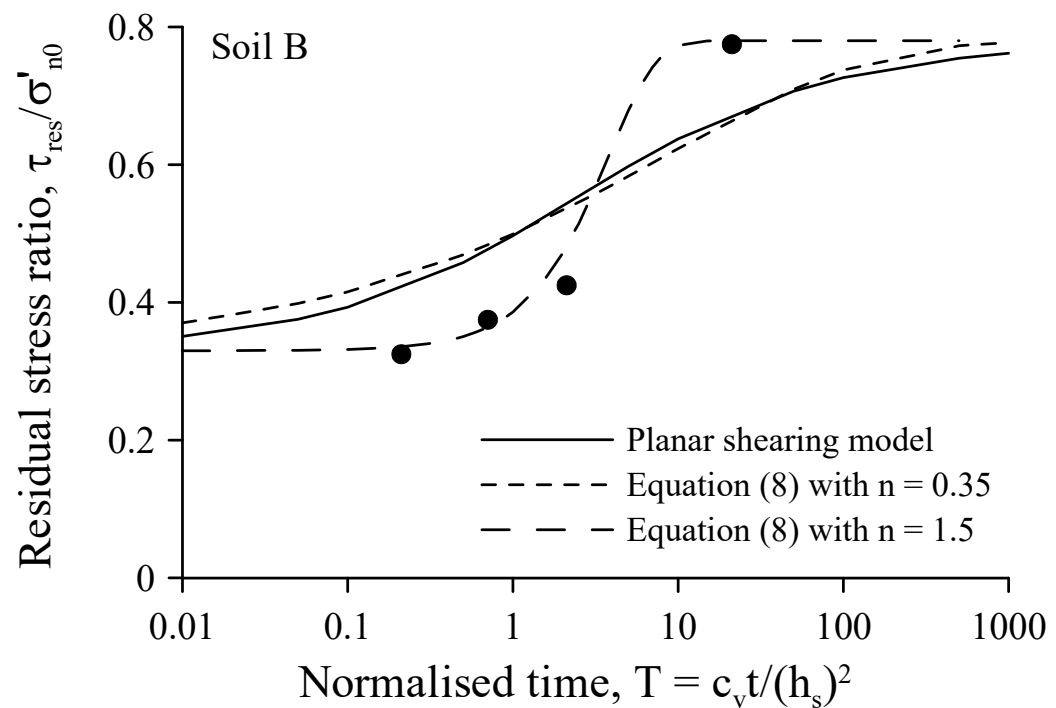

(b)

Figure 11: Variation in interface resistance with dimensionless time $T=c_{v} t /\left(h_{s}\right)^{2}$ : (a) Soil A, (b) Soil B 


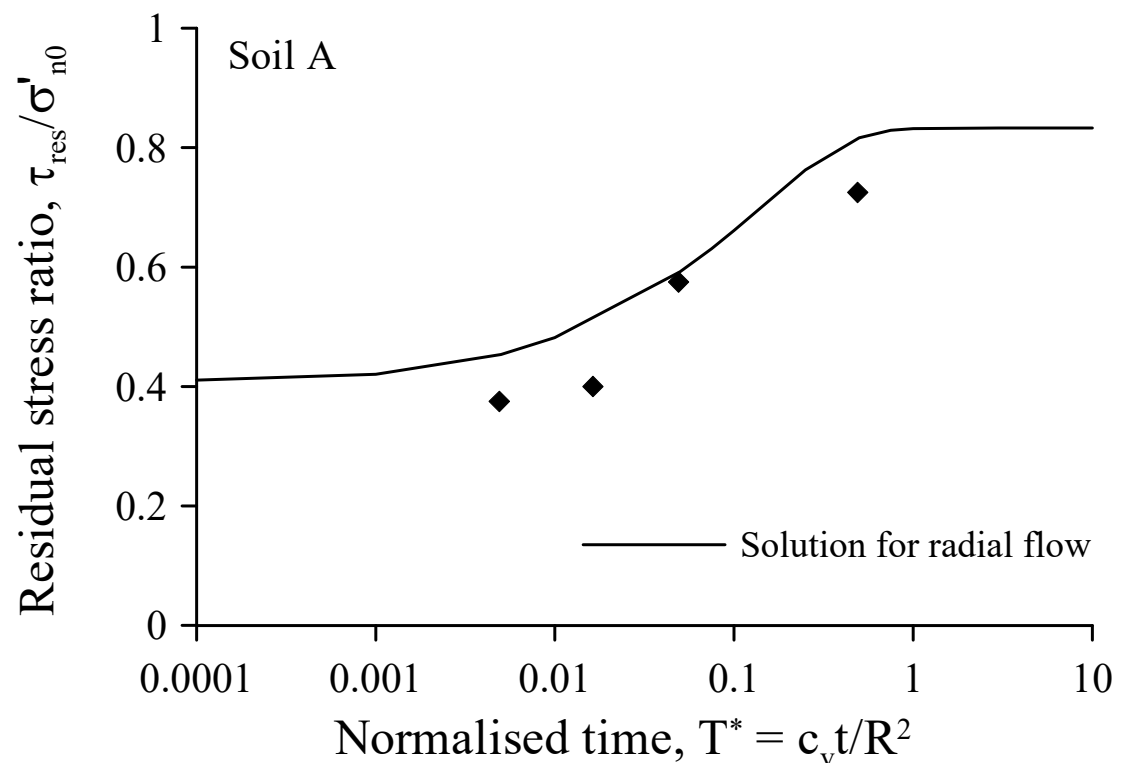

(a)

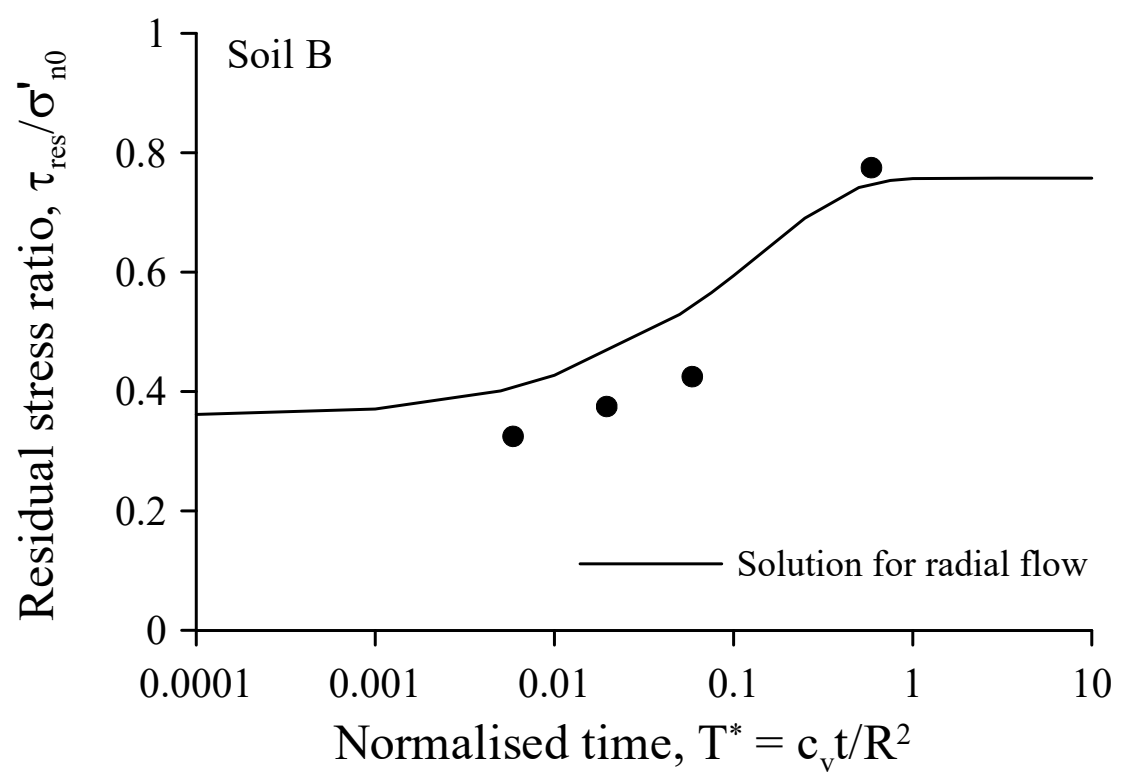

(b)

Figure 12: Variation in interface resistance with dimensionless time $T^{*}=c_{v} t / R^{2}$ : (a) Soil A, (b) Soil B 


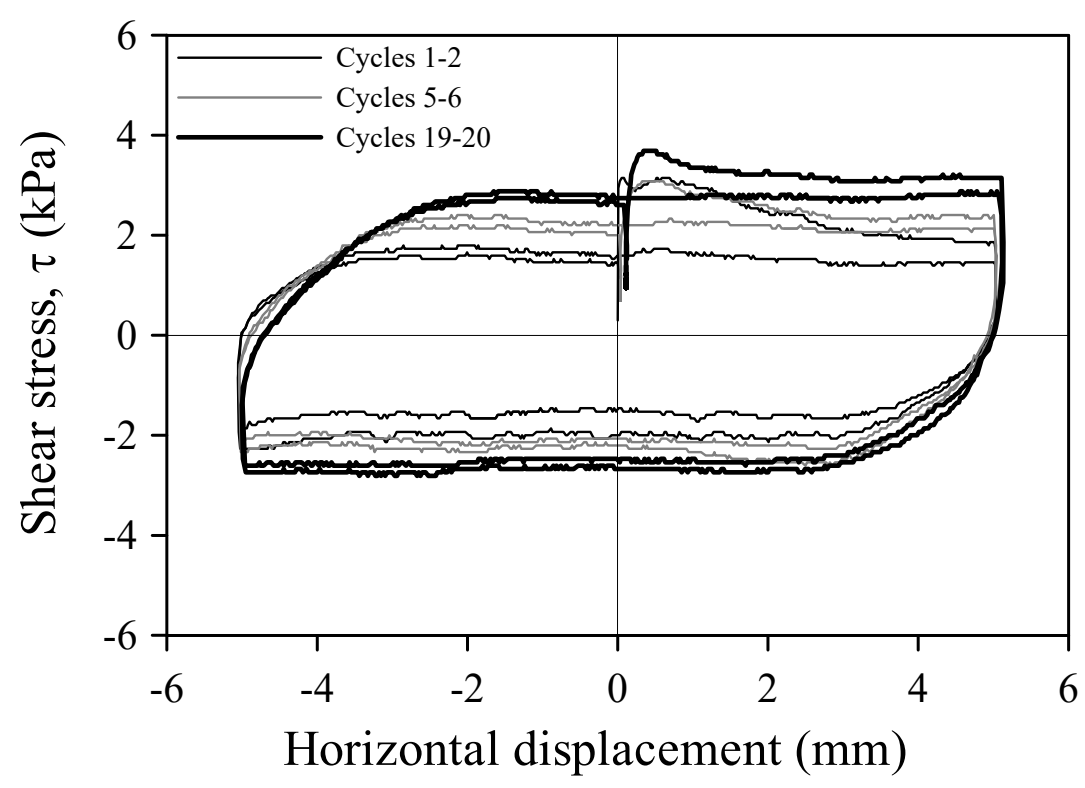

(a)

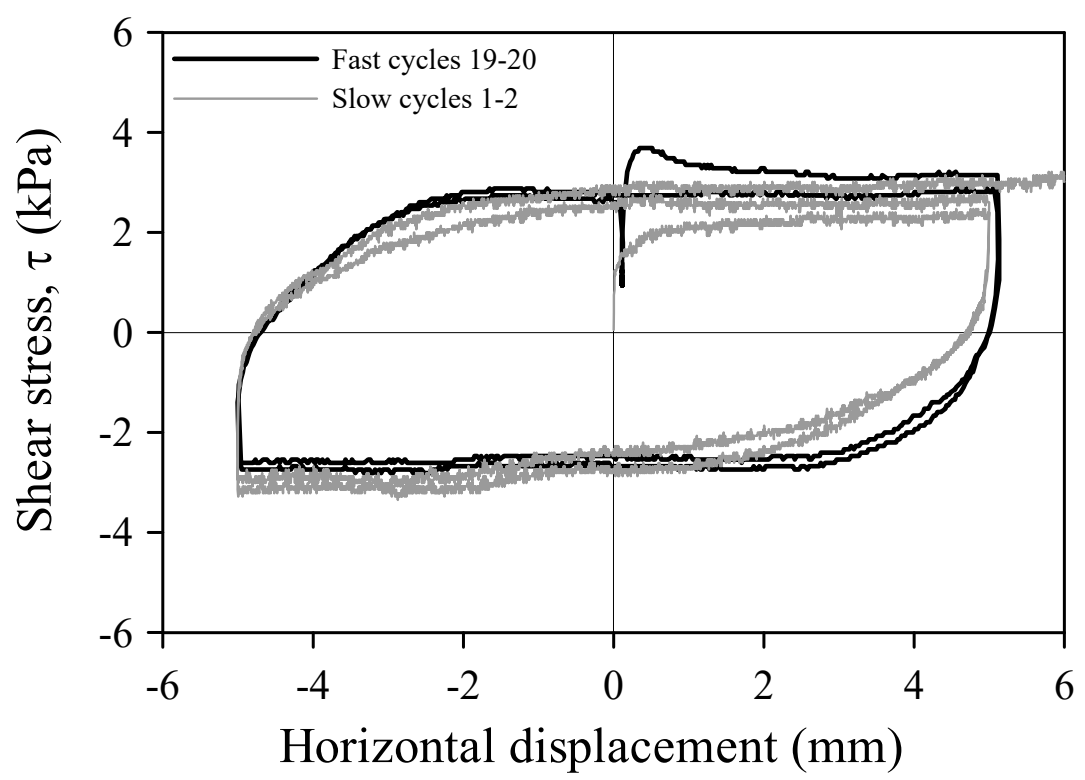

(b)

Figure 13: Consolidation hardening for Soil A: (a) Fast test (Test 5), (b) comparison of final cycles of fast test and slow test (Test 1) 


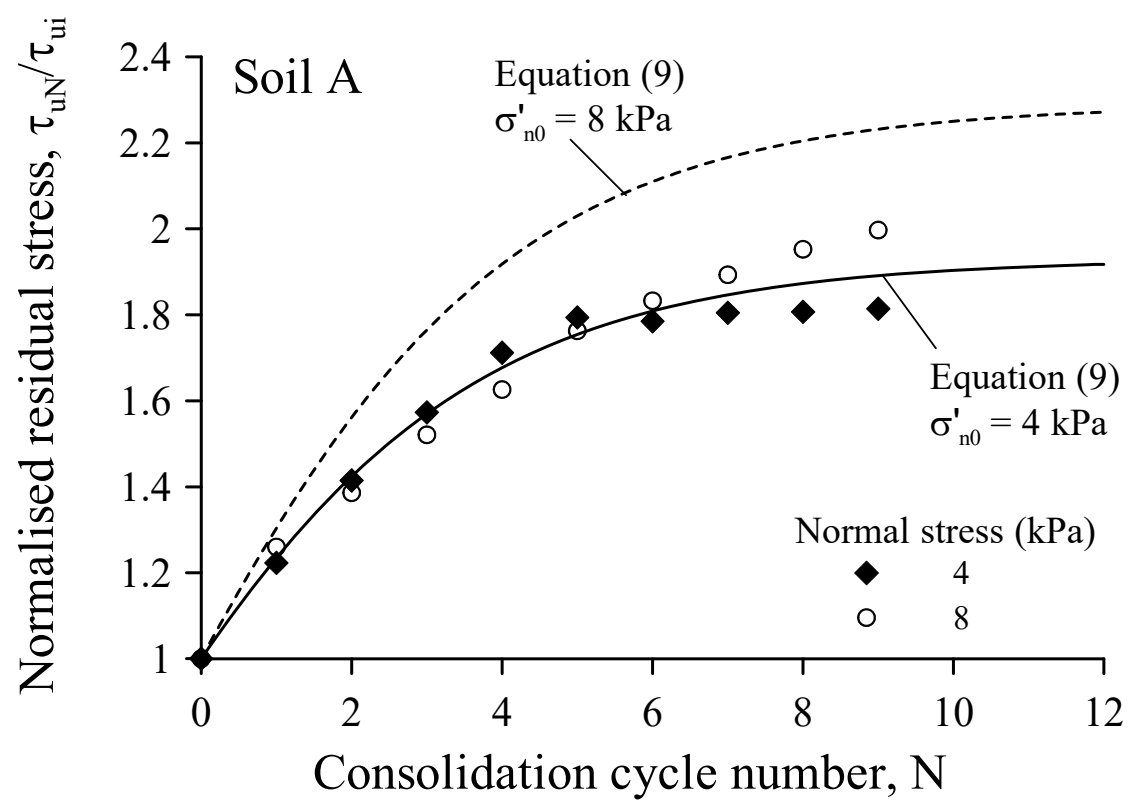

(a)

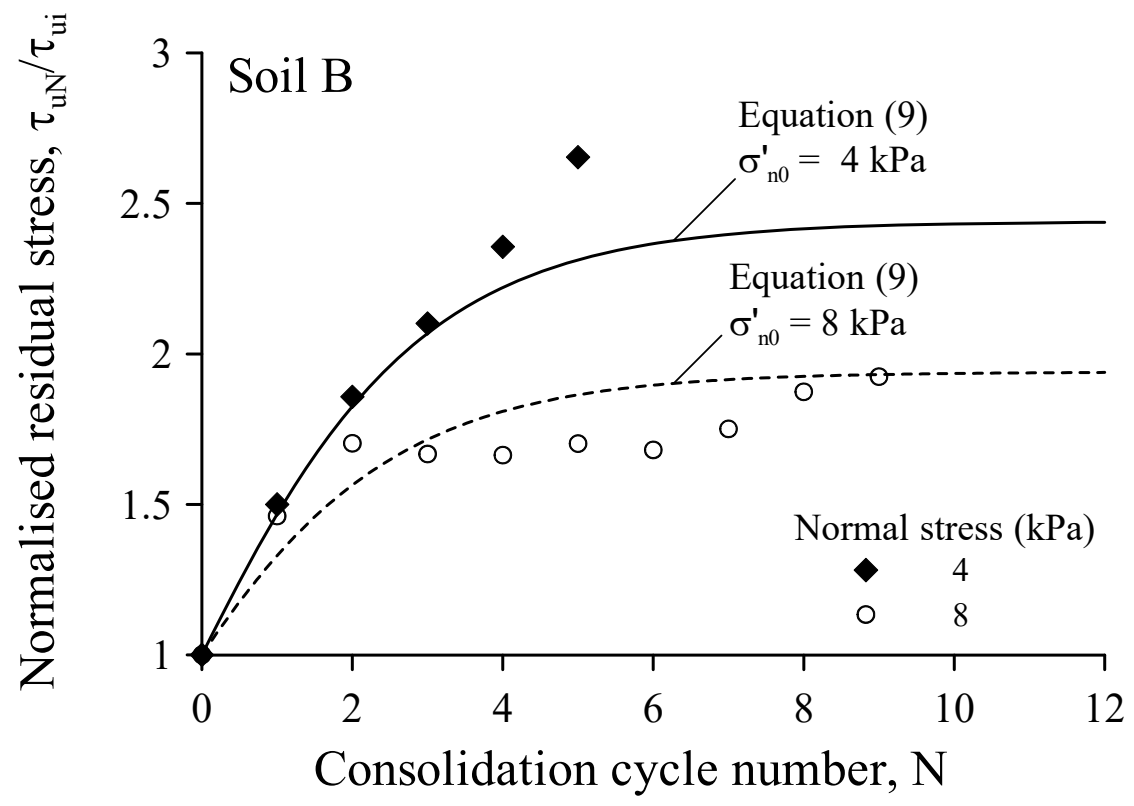

(b)

Figure 14: Normalised resistance vs consolidation cycle number for fast episodic tests: (a) Soil A, (b) Soil B 


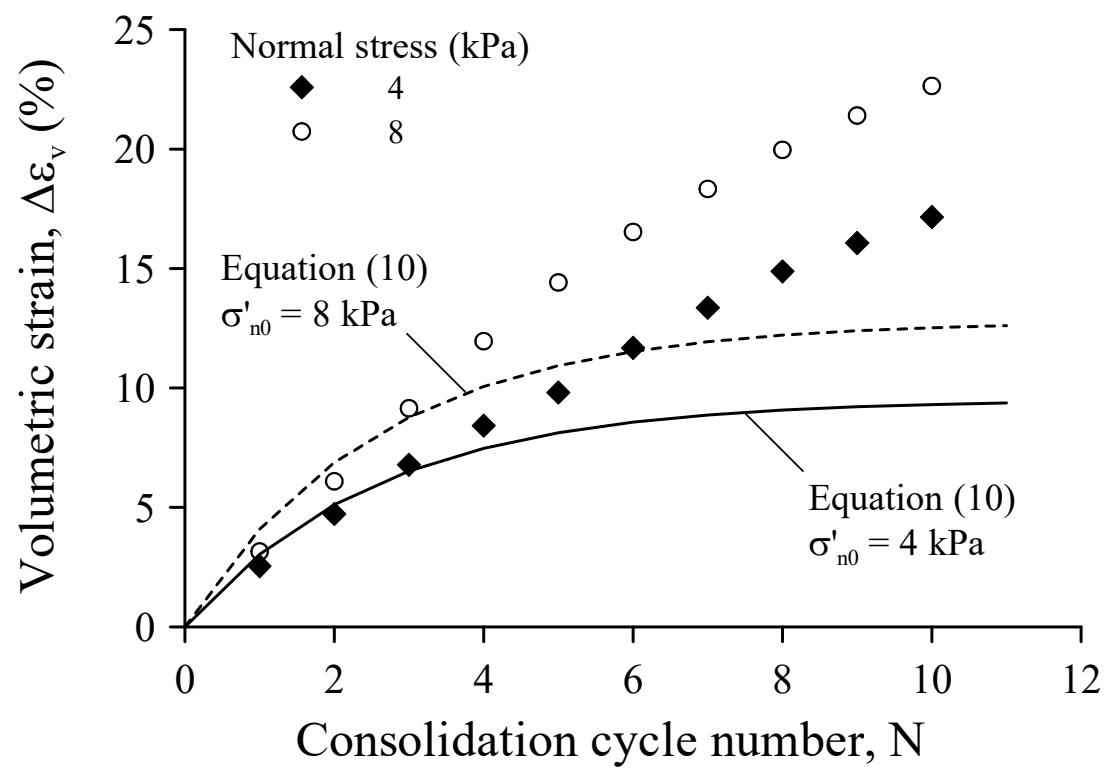

Figure 15: Volumetric strain vs consolidation cycle number for fast episodic tests on Soil A 


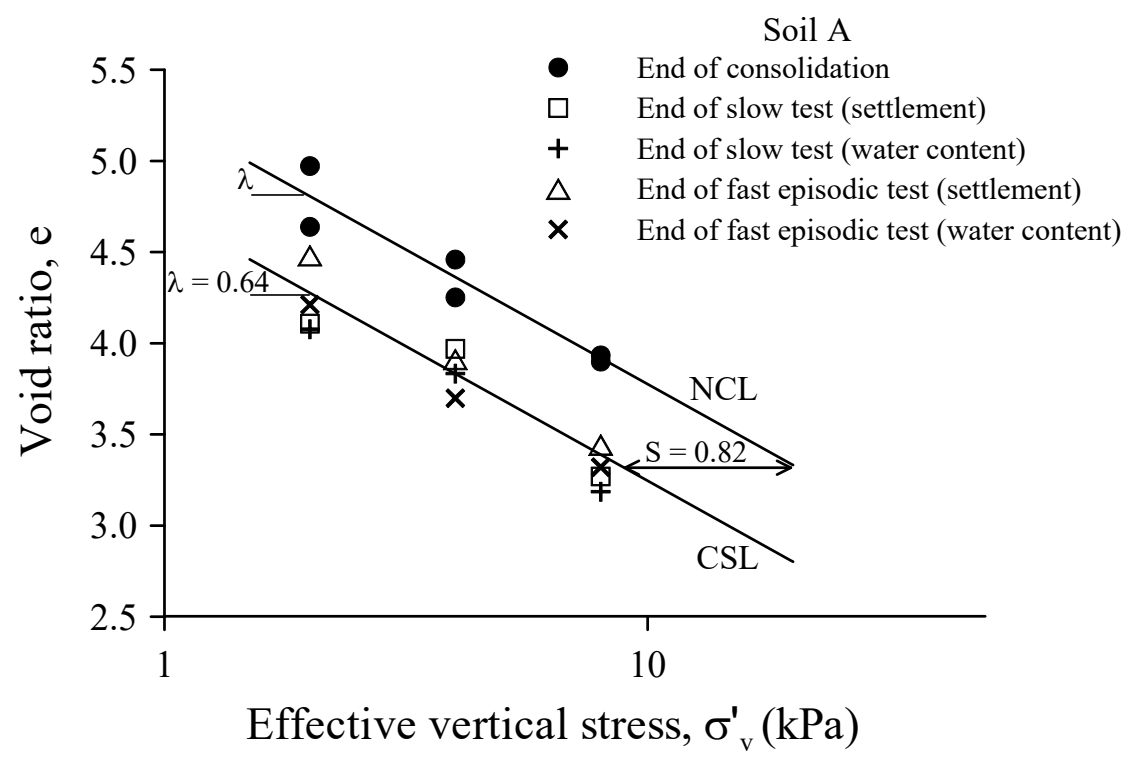

(a)

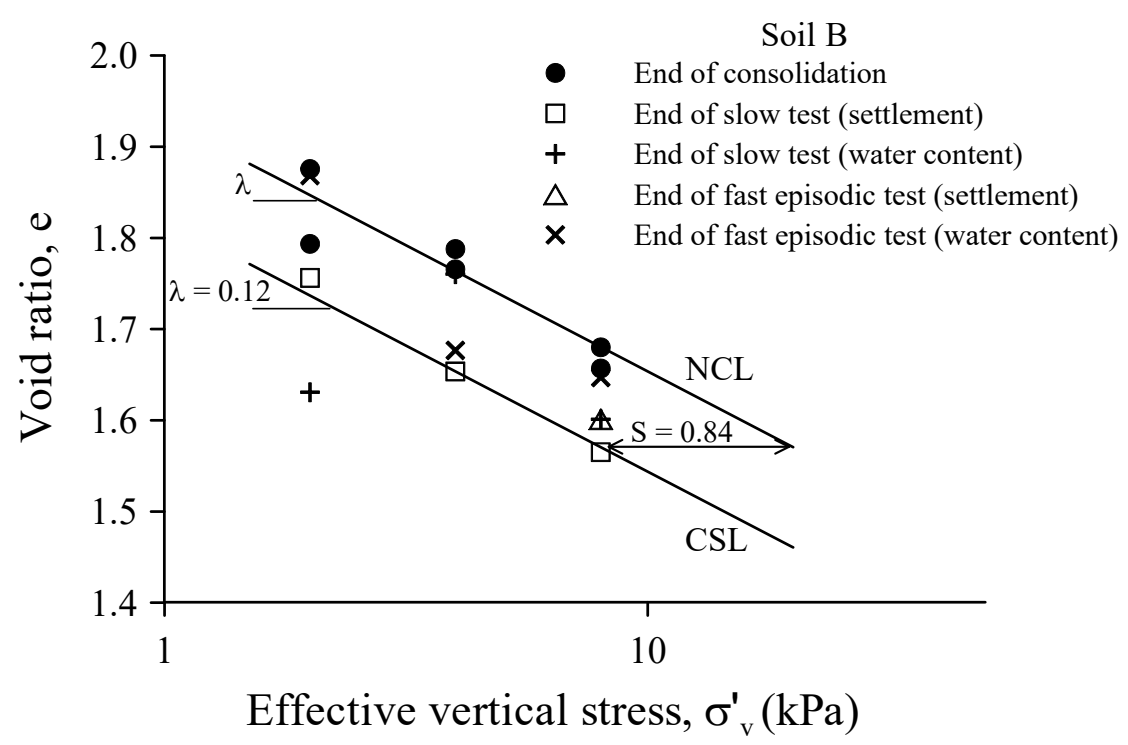

(b)

Figure 16: Normal compression line and critical state line: (a) Soil A, (b) Soil B 